\title{
Comparing GA, DE and ACO for Vendor Managed Inventory Optimisation
}

\author{
Eric Ross Pearson - Student Number: 101586682 \\ Supervisor - Prof. Ryszard Kowalczyk \\ Faculty of Information and Communication Technologies \\ Swinburne University of Technology \\ PO Box 218, Hawthorn, Melbourne, Australia 3122
}

\section{INTRODUCTION}

Vendor Managed Inventory (VMI) is a service provided by many Vendors where customers relinquish control over inventory sourcing processes to their vendors. Under a VMI service, the relationship between Vendor and Customer should typically be trusting and symbiotic with both parties benefiting financially (McAdam \& Keogh, 2004). Finding and adopting ways to improve that benefit is widely researched with numerous different approaches investigated. Furthermore, with most markets experiencing unprecedented changes in technology and methodology, Vendors must continue to adapt towards innovative solutions to retain competitiveness (Disney \& Towill, 2003; Dyer \& Singh, 1998; Gao, Xu, Ruan, \& Lu, 2017).

Artificial intelligence techniques are commonly applied to VMI and Supply Chain (SC) problems and have proven to provide viable solutions. There is significant research addressing such problems using a variety of Al approaches. However, it does not appear that there is literature that specifically compares the three chosen Al metaheuristics in this setting.

Given that there is significant diversity in type and number of SC problems, VMI has been selected to provide a focused scope which can be extrapolated upon to reflect a wide number of general SC problems.

\section{Methodology}

This study looks to understand the appropriability of certain Al techniques at optimising a VMI fulfilment problem. To achieve this, the following sub problems were addressed: (1) determine which Al techniques are more suited for the kind of problem described in section 4. PROBLEM AND ITS SETTING; (2) Investigate the identified techniques and develop algorithms that support the data and problem; (3) Understand the problem; and (4) Run the algorithms and analyse the results.

Sub problem (1) - To determine the suitability of Al techniques, a survey of available literature was performed. Cases where literature have attempted to address a Supply Chain optimisation problem using an Al technique were counted. Only the Genetic Algorithms (GA) and Ant Colony Optimisation (ACO) techniques had been applied more than once to VMI optimisation problems, and on that basis, they were selected for comparison within this study. Differential Evolution (DE) was also selected as a novel application of a continuous space optimisation technique against a discrete problem. The results of the survey can be found in appendix A.

Sub problem (2) - An in-depth literature review was then performed on the three selected Al techniques regarding Supply Chain optimisation adaptions. The literature review identified what approaches have been investigated by the academic community and what elements of those approaches could be incorporated into the algorithms developed for this study. It is also important to 
note that in all cases the original techniques of the Al Approach authors have been adopted (ie. In the case of ACO - Ant System (Dorigo \& Gambardella, 1997)). Each of these "original" techniques were experimented with to determine a feasible implementation for this specific problem. However, the author acknowledges that the comparisons performed in this paper can only be against each of these original techniques and that more modern techniques (ie. In the case of ACO - Ant Colony System (Dorigo, 2004)) may well yield improved results. Sections 2. REVIEW OF THE RELATED LITERATURE and 5. APPLICATION thoroughly document this sub problem. The results of the in-depth literature review were recorded in tabular format with attention being given to supply chain features, this helped to identified techniques that suited the model selected for this research. The results of the detailed literature review can be found in appendix B.

Sub problem (3) - Gaining an understanding of the problem was achieved by working closely with an industry partner that specialises in the distribution of mobile phones. The problem data, model and constraints have been adapted to provide a constrained yet realistic interpretation of the company's real-world problem. Only a single set of rules/data has been provided which limits the scope of comparison of each technique, however provides an opportunity for future studies to expand on the findings of this research paper. The problem and its setting have been documented in section 4 . PROBLEM AND ITS SETTING.

Sub problem (4) - Each of the algorithms were run multiple times against the singular data set with the results been captured in tabular format and graphed, these results are analysed and discussed in section 6. EXPERIMENTAL RESULTS.

This paper is organised as follows: Section 2 reviews the related literature, Section 3 details the assumptions and nomenclature, Section 4 is a detail explanation of the problem, Section 5 details the implementation of the Al techniques, Section 6 discusses the experimental results and this paper is concluded in Section 7.

\section{REVIEW OF THE RELATED LITERATURE}

Vendor Managed Inventory (VMI) is a widely-researched topic, a claim that is easy to substantiate given the number of articles and research papers that contain VMI in the title. Many researchers have chosen to investigate how various forms of artificial intelligence can be applied to different VMI Models (Akbari Kaasgari, Imani, \& Mahmoodjanloo, 2017; Diabat, 2014; Kastsian \& Mönnigmann, 2011; Kristianto, Helo, Jiao, \& Sandhu, 2012). Results of prior research indicate that Al can be applied to VMI models and that correct application of Al has the potential to provide economic benefits that can outperform traditional methods (Borade \& Sweeney, 2014; Kwak, Choi, Kim, \& Kwon, 2009; SueAnn, Ponnambalam, \& Jawahar, 2012).

A review of available literature shows us that there are many options for addressing optimisation problems within a Supply Chain setting. This paper examines literature regarding prevalent metaheuristic optimisation methods used within Supply Chain Optimisation problems: Genetic Algorithms, Differential Evolution, and Ant Colony Optimisation.

This section describes three frequently referenced Al techniques that the literature review has identified to have applications in VMI and Supply Chain problems. All three techniques are local search metaheuristics that share common behaviour, this common behaviour includes: a fitness function that measures the performance of a candidate solution, a population of candidates that are dispersed (randomly or otherwise) across the search space, a function that modifies, perturbs, or cross pollinates which either alternates the candidates position or creates a new candidate with a new position, a method for selecting the fittest candidates for the subsequent generation based on their fitness function, repeating of this process through subsequent generations to find improved positions within 
the search space, and finally, the application of parameters that can tune the rate of exploration vs exploitation.

\section{Genetic Algorithms (GA)}

Genetic Algorithms (GA) are metaheuristics that follow the principles of natural evolution, using selection, crossover and mutation. Popularised by John Holland in the 1970's (Holland, 1984, 1992) and David E. Goldberg in the 1980's (Goldberg, 1989). A population of candidates competes with one another for the right to contribute genetic code to the next generation, typically with the fitter candidates within a population succeeding. As subsequent generations are created the overall fitness of the population generally improves. Once exit criteria is met (ie. maximum number of generations) the candidate with the highest fitness is chosen as the solution.

The method of implementing GAs defined by Goldberg covers initialisation, selection, crossover and mutation. Initialisation is the creation of the starting population of candidates that are dispersed within the search space (generation 0). Selection is the process of choosing which candidates are selected to reproduce to create the next generation. Each candidate is measured for fitness and candidates with a higher fitness have a higher probability of reproducing. The selected candidates pair off with one another to create child candidates (the next generation) in a process known as crossover. To explain how this can be achieved we will consider candidates that consist of a single binary dimension, a random number is used to find a position along the binary sequence, all binary digits before the position are retained while all binary digits after the position are taken from the other parent. Together this produces a child candidate that comprises of information (DNA) from both parents.

A degree of mutation is applied during or after the crossover process, in our binary example, this is achieved simply by applying a very small probability factor (adjustable depending on the level of exploration required) an individual bit will swap from a 0 to a 1. this mechanism speeds up exploration of the search space and acts as a failsafe to prevent the population becoming tracked in a local optimum. The selection, crossover and mutation steps are repeated until exit criteria is met (ie. number of generations, minimum fitness is found, or stagnant population in which the population fitness does not improve after subsequent generations). This process can also be applied to discrete and continuous dimensions using altered mechanics.

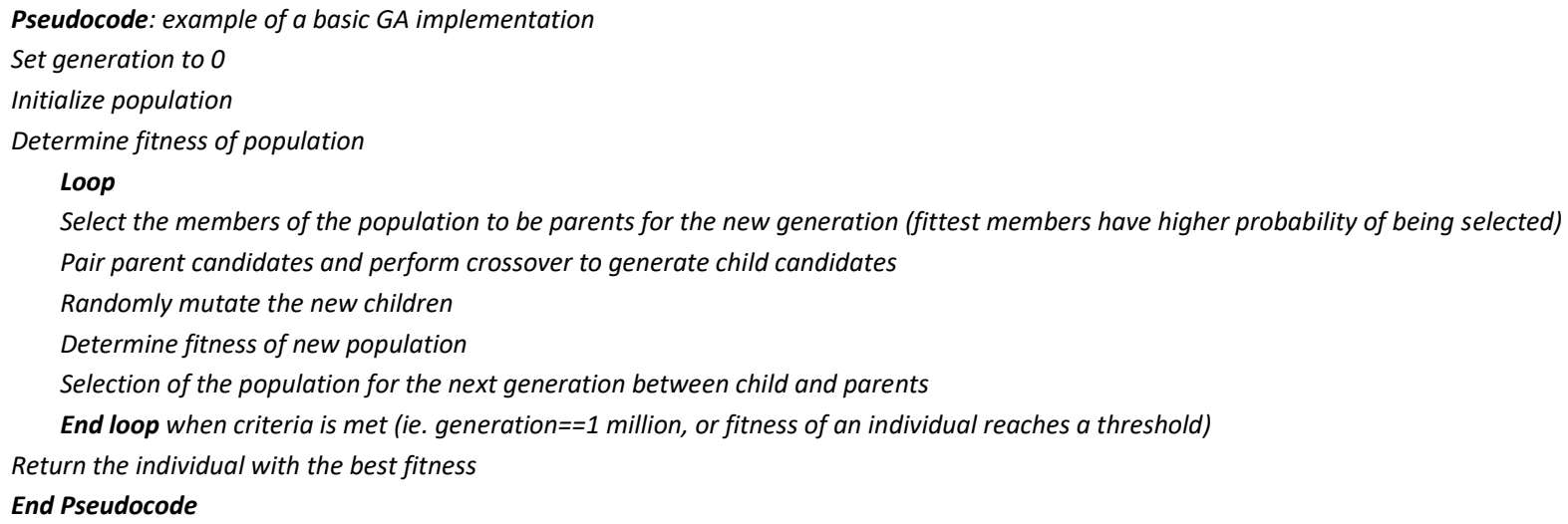

GAs have been found to be the most prolific metaheuristic applied in the reviewed material and have been used to solve a number of VMI optimisation problems (Pasandideh, Niaki, \& Nia, 2011) (Mondal \& Maiti, 2003). They are frequently applied in comparisons between other methodologies, for example in Nia (Roozbeh Nia, Hemmati Far, \& Akhavan Niaki, 2014). Furthermore, GAs are useful for 
finding optimal input parameters for a variety of models. Chi (Chi, Ersoy, Moskowitz, \& Ward, 2007), (Lin, Chang, Hung, \& Pai, 2010)

They are natively suited at finding binary and discrete decision variables, Goldberg (Goldberg, 1989). In some cases finding an appropriate representation for the decision variables is a significant challenge, Sue-Ann (Sue-Ann et al., 2012) found that a single amalgamated binary vale was an effective representation of the decision variables for a problem. Park (Park, Yoo, \& Park, 2016) made use of $2 x$ integer matrices.

GAs were found to be useful for multi modal and multi objective optimisation problems Ortiz (Ortiz, Simpson, Pignatiello, \& Heredia-Langner, 2004). NSGA-II is an example of a multi objective GA variant applied by Liao (Liao, Hsieh, \& Lai, 2011) and Deb (Deb, Pratap, Agarwal, \& Meyarivan, 2002).

Cárdenas-Barrón (Cardenas-Barron, Trevino-Garza, \& Wee, 2012) proved that GAs were at risk of being inappropriately applied to cases where a heuristic or equation may exist that can solve the optimisation problem far more effectively than a metaheuristic.

GA approaches to optimisation have shown to reduce costs, improve profit, vehicle utilisation and service levels as well as reducing the bullwhip effect. Borade (Borade \& Sweeney, 2014), (Disney \& Towill, 2003)

\section{Ant Colony Optimization (ACO)}

Ant Colony Optimization (ACO) is a combinatorial optimisation metaheuristic that draws its concepts from ant colony behaviour, conceptualised by Marco Dorigo (Dorigo, 2004; Dorigo \& Gambardella, 1997). The analogy follows that a colony of ants searching for food have path segments (also known as routes) that they may choose from to reach the food. Each ant starts somewhere in the search space and will probabilistically chose a route with their decision being influenced by existing pheromone trails and heuristic information (such as distance). Ants will repeat this process for subsequent routes to complete their journey (also known as a tour). Ants that find the shortest tour will leave the strongest pheromone trails (which in turn increases the likelihood that successive generations will choose some or all the routes along that tour). All pheromone trails dissipate over time, so only trails that have an influx of new pheromones will continue to influence ants. This process is repeated through successive generations until the ants all converge on a single tour or a certain generations threshold is reached.

The Traveling Salesman Problem (TSP) is typically used to illustrate how ACO can solve a combinatorial optimisation problem. In a TSP, a travelling sales person is required to travel to multiple cities but must find the shortest path between them all.

ACO applies the ant colony concept to determine the sequence of cities that will yield the shortest tour. Ants start at a randomly selected (evenly distributed) city and may move to any other city that they have not previously visited. Each ant probabilistically choses the sequence of cities they will travel to, to complete the tour (with higher probabilities directed to routes with heavier pheromone trails and heuristic information). The ants that completed their trips the fastest - add stronger pheromone trails to the routes that make up their tour. Subsequent generations repeat the process and have a higher probability of following routes with stronger pheromone trails. Routes with weaker pheromone trails will evaporate and become less likely to attract ants. Eventually all ants will converge to the same sequence of cities (solution will stagnate). 


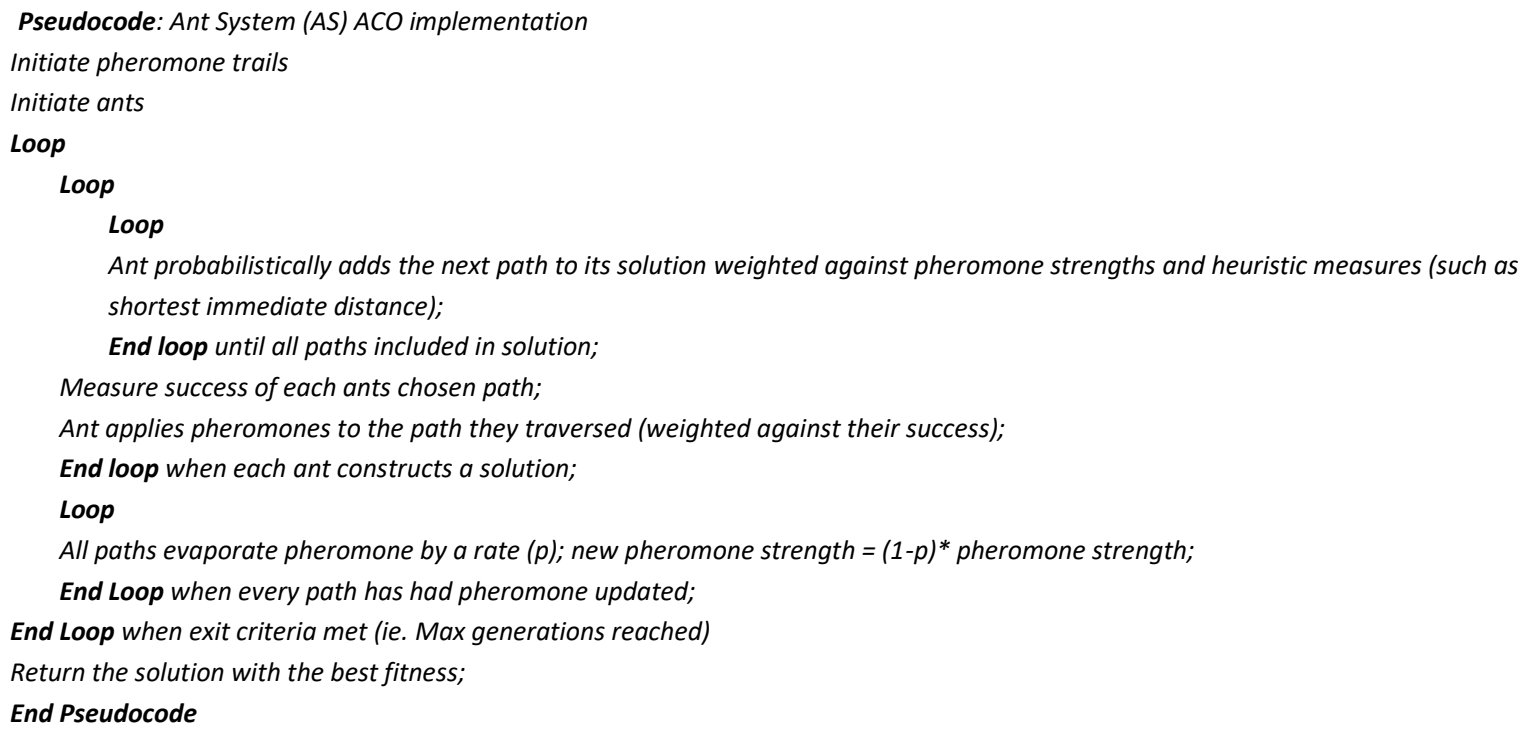

ACO is natively suited to discrete optimisation problems (Marco Dorigo (Dorigo, 2004)) and is often favoured for multi objective optimisation problems. For example, Moncayo (Moncayo-Martínez \& Zhang, 2011) applied Pareto ACO (P-ACO) to solve a multi objective SC optimisation problem. The decision variables are defined as the selection of activity and resource for each node within the supply chain. P-ACO has been designed as mechanism to deal with multi objective optimisation (MOO) problems by finding balanced solutions (known as non-dominated solutions) where further improvement to any objective will be detrimental to any of the other objectives. Similarly, Arora (Arora, Chan, \& Tiwari, 2010) applied Dynamic-ACO to solve a cost minimisation/customer satisfaction maximisation VMI problem.

ACO has also been successfully applied to single objective optimisation problems, for example Nia (Roozbeh Nia et al., 2014) proposed an adaptive fuzzy control application to calculate demand in solving a EOQ single-buyer single-supplier VMI problem. ACO was used to optimise the shipments to vendor customers by minimising the supply chain cost (limited by multiple constraints). Three decision variables were sought by the ACO algorithm: the order quantities, the maximum backorder level, and the number of pallets for each order to minimize costs while ensuring constraints were satisfied. Nia's work is of interest as the model studied in Nia's work has some similarities to the one described in this research paper.

One more interesting adaption of ACO in supply chain space was conducted by Silva (Silva, Sousa, Sa Da Costa, \& Runkler, 2004) who proposed to use ACO for a multi agent modelled supply chain. Where each agent in the supply chain attempts to locally optimise its own problem using ACO and simultaneously permitting communication between agents via a shared pheromone matrix to identify an optimally shared solution. 


\section{Differential Evolution (DE)}

Differential Evolution (DE), proposed by Storn and Price (Price, 2005), is a stochastic population search optimisation metaheuristic abstractly like GAs as it also draws its operations from the concepts of natural evolution. The most significant difference between GAs and DEs lies in the recombination/crossover approach. with DEs the recombination approach involves the weighted difference between two randomly selected candidates being applied to a third candidate, thus perturbing the third candidate's location in the search space.

Like the other metaheuristics defined here, a population of candidates is initialised and in the case of Storn and Price's definition, randomly selected but uniformly distributed among the search space. Mutation is the first operation to be applied to the population and it differs significantly from the GA construct. Each candidate is cloned and then perturbed (mutated) so that it differs from its original. The perturbation is achieved by selected 2 further candidates randomly from the population. The difference between each dimension of these 2 random candidates is calculated and then multiplied by a mutation factor (proposed to be between 0 and 1.2 (Price, 2005)) this factor weights the size of the mutation step and will control how quickly the solution ascends local optima.

Each candidate is then combined with its mutated clone. each dimension of each candidate is randomly tested for crossover, should the test pass the, that dimension is updated with the new mutated dimension value. This is repeated for all dimensions of all candidates. At least one dimension should be changed to its mutated value. A Crossover factor provides the user control over how likely each dimension will crossover. This should range from 0-1. 0 meaning only one dimension will ever crossover and 1 meaning all dimensions will crossover.

Finally, a fitness function must be applied to both the original candidate and the mutated clone. The candidate with the highest fitness score is retained. Once the selection criteria is met, ie. once a selected number of generations has occurred, or a fitness function threshold is met then the candidate with the highest fitness function is returned.

Pseudocode: basic DE implementation

Generate initial population of candidates

Loop

Loop

Select 3 other distinct candidates from the population ( $n 1, n 2$ and $n 3)$;

Create a clone of candidate $n 1$;

Loop

Clone candidate dimension $=n 1$ dimension + mutation factor $*(n 2-n 3$ dimension $)$

Randomly choose between existing candidate dimension and new candidate dimension base on a crossover factor.

End loop after all dimensions

Compare the existing candidate with the modified clone candidate. The most successful is included for the subsequent

generation.

End loop after all candidates in the population

End Loop when exit criteria met (ie. Max generations reached)

Return the solution with the best fitness;

End Pseudocode 
Differential evolution was found to be the least investigated of the three metaheuristics in terms of SC applications, although examples do exist such as (Wisittipanich \& Kachitvichyanukul, 2012) to solve job shop scheduling problems. While it is natively suited to continuous optimisation problems (Price, 2005), (Das, Mullick, \& Suganthan, 2016), (Voratas, 2012) it is possible to adapt DE's for discrete optimisation problems as shown in (Pan, Tasgetiren, \& Liang, 2008), in fact SC problems could well contain a combination of both discrete and continuous variables in which case methods for mixed discrete/continuous optimisation methods using DE could also be applied (Lampinen \& Zelinka, 1999).

Specifically for VMI problems Nia (Roozbeh Nia et al., 2014) applied Differential Evolution to solve a single objective optimisation problem (cost minimization) although it is not immediately obvious how this was implemented to support discrete decision variables. Both Shafieezadeh (Shafieezadeh \& Sadegheih, 2014) and Routroy (Routroy \& Kodali, 2005) applied Differential Evolution to address a three echelon VMI problem, and were able to avoid the problem of discrete variables by representing the variables as continuous. However, there does not appear to be an example where DE's were used specifically to solve discrete variable VMI problems.

\section{ASSUMPTIONS AND NOMENCLATURE}

The following assumptions are applicable for this paper:

- The demand for Mobile phones from retail locations is stochastic;

- Freight between vendor and customer will be instantaneous;

- Backorders are not allowed;

The following terms have been defined for this paper:

- Vendor Managed Inventory (VMI) is a service provided by Vendors where customers relinquish control over inventory sourcing processes to their vendors. In the case of this proposal, VMI refers to a model in which vendors auto replenish inventory to retailers without any input from the retailers;

- Retailers/customers are organisations that purchase inventory from vendors and then resell that inventory on to end consumers;

- The retail channel refers to all retailers;

- SKU stands for Standard Kitting Unit which is supply chain terminology for a unique product;

- Vendors/suppliers are organisations that distribute inventory to customers;

- Artificial Intelligence approaches (AI approaches) - any technique presented as Al by the scientific community where discourse related to the approaches can be readily found within journal entries from the last 20 years;

- Optimisation is the process of finding an optimal solution which will be determined by measurable output variables of the VMI model.

- Heuristic. A time and/or effort practical methodology for solving a specific problem to find a suitable but not necessarily optimal result. Examples of heuristics include applying a rule of thumb, educated guesses, intuitive judgments, etc.

- Metaheuristic. A general problem-independent framework that is heuristic in nature which can be applied to many problems. All metaheuristic techniques listed in this paper require two things: representing each candidate in a population numerically and mathematically measuring the fitness of the candidates.

- Candidate: A potential solution to a problem.

- Dimensions: Candidates have $\mathrm{n}$ number of attributes (mapped numerically) referred to in this paper as dimensions. All candidates in a population have the same number of dimensions. 


\section{PROBLEM AND ITS SETTING}

In the context of this research paper we are going to consider a VMI model that is offered by a supplier as a service to a Mass Market Retailer (MMR) or Telco. The implication of such a model is that the supplier is concerned primarily with maximising the benefit to the retailer above consideration for any advantages that it may offer the supplier (such as reducing the Bullwhip effect). This paper will not explore any competing or symbiotic advantages that the supplier may have the opportunity to leverage when operating such a model.

Figure 1 - VMI Model provides a diagrammatic representation of the end to end flow of the model.

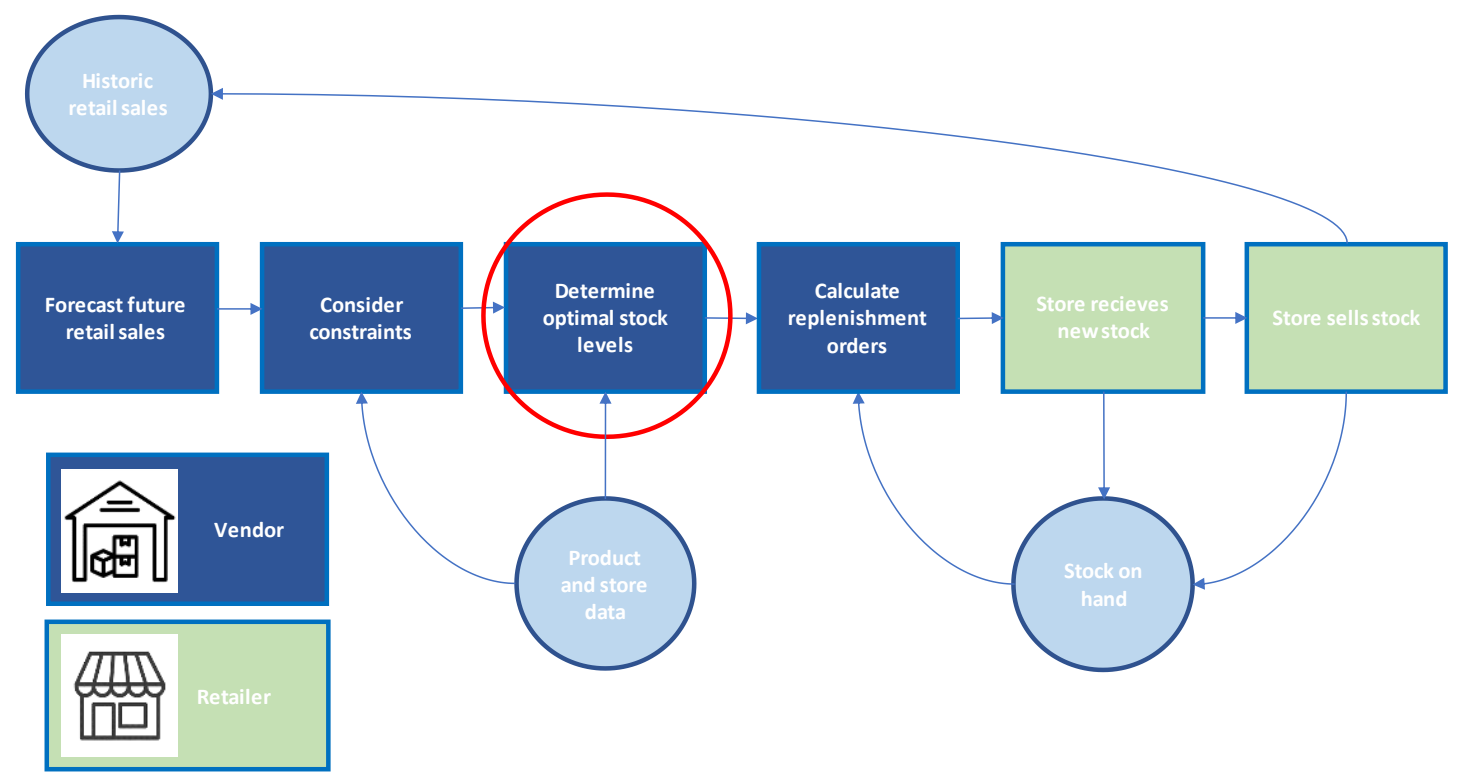

Figure 1 - VMI Model

Historic retail sales are the sales velocity of inventory thru the retail channel; Product and store data includes the cost and price of the products at each store and any data required to calculate constraints; Stock on hand are the current inventory levels within the retail channel; Forecast future retail sales is the process of taking historic sales and converting it into a future forecast; Considering constraints takes constraint related data from the Product and store data feed and applies it to the optimisation process; Determine optimal inventory levels is the optimisation process that requires, cost and price data, constraints data and the forecast in order to search for an optimal or near optimal solution; Once the ideal or near ideal inventory levels are known, replenishment orders are calculated to determine how much stock should be shipped to each store to ensure they have the optimised inventory levels; The retails stores will receipt new stock in order to sell it, all sales will deduct stock levels at the retailer and increase their historic retail sales (to be applied to future iterations of the model);

The model only forecasts the stock requirements of each retailer for the next day, given the assumption that freight times are instantaneous, the model will be run daily to ensure that stock arrives just in time and so future time periods do not need to be forecast for. Given a noninstantaneous freight time, this model could be easily adjusted from a daily fulfilment process to a weekly fulfilment process (assuming no freight times were greater than 7 days) and the concepts explored would remain the same. As it is not the intent of this paper to investigate forecasting methods, the forecast method chosen is very naïve and does not consider what day of the week it is, seasonal trends, product trends or any other factor that might influence the sales forecast. 


\section{Forecasting methodology}

The mean and standard deviations of each product/store combination are calculated across the entire period that is provided in the input file. The import file does not consider dates and assumes each line that has the same store and SKU combination, represents a distinct day. Furthermore, there is no validation to ensure that the input file is constructed correctly. Given this, it is important that the file provided consists of a complete data set. The means and standard deviations are used to calculate a normal probability distribution for each store and SKU combination, which are then inversely cumulated to generate a probability matrix for every possible quantity value. This concept is demonstrated by calculating a normal distribution with a mean of 3 and a standard deviation of 2 in table 1.

Table 1 - Inverse Cumulative Probabilities

\begin{tabular}{|c|c|c|c|c|c|c|c|c|c|}
\hline Quantity: & 0 & 1 & 2 & 3 & 4 & 5 & 6 & 7 & 8 \\
\hline $\begin{array}{l}\text { Probability to sell } \\
\text { exactly: }\end{array}$ & $6.48 \%$ & $12.10 \%$ & $17.60 \%$ & $19.95 \%$ & $17.60 \%$ & $12.10 \%$ & $6.48 \%$ & $2.70 \%$ & $0.88 \%$ \\
\hline $\begin{array}{l}\text { Probability to sell } \\
\text { at least: }\end{array}$ & $95.88 \%$ & $89.40 \%$ & $77.30 \%$ & $59.70 \%$ & $39.75 \%$ & $22.15 \%$ & $10.05 \%$ & $3.58 \%$ & \\
\hline
\end{tabular}

The probability to sell at least $z$ is the inversely cumulated probability calculated from the normal distribution above it. In the above example, we are $89.40 \%$ likely to sell at least 1 item. Note that we are in fact $100 \%$ likely to sell at least 0 items, however this is reflected as $95.88 \%$ in the above table because the table does not include probabilities for negative amounts. This factor is corrected in the actual implementation.

Any quantities that have less than a $5 \%$ chance of selling are excluded. $5 \%$ is a practical selection (although not tested empirically) to ensure the likelihood of finding the optimal solution without having an excessing large number of possible dimension options.

The problem construct can be defined as follows:

- There is a single supplier and a single Mass Market Retailer (MMR);

- The MMR has y retail locations;

- There are x SKUs;

- There is no constraint to which products can be sold at which store, in other words all products will be available at all stores;

- The supplier has unlimited inventory;

- Transit times between the supplier and retailer are instantaneous (lead time $=0$ );

- Back orders are not allowed;

- Inventory is replenished daily for the next subsequent day;

- The model only considers the next subsequent day and not future replenishment requirements;

- Retailers demand is stochastic;

- Prices and costs are fixed for the replenishment day; 


\section{Mathematical formula}

The notation for this model is as follows:

- $x$ index of retailer

- $y$ index of product

- $z$ index of product quantity

- $q_{x y}$ quantity of product $x$ required at store $y$

- $d_{x y}$ demand of product $x$ at retailer $y$

- $\quad p_{x y z}$ probability that product $x$ at retailer $y$ will sell at least $z$ items

- $\quad m_{x y}$ marginal 3PL cost to warehouse and ship product $x$ to store $y$

- $c_{x}$ cost per unit of product $x$

- $o_{x}$ obsolescence risk of product $x$

- $h_{x}$ holding cost of product $x$

- $v_{x y}$ sales value of product $x$ at store $y$

- $B$ total budget of the MMR

- A total availability target of the MMR

- $R$ ratio of total inventory cost to total inventory profit

- P total profit

- I total income from all sold goods

- C total purchase and 3PL costs of all products

- $O$ total cost of products due to obsolescence

- $\quad H$ total cost incurred by holding products not sold

- $\quad \mathrm{i}$ is the number of stores where store $\mathrm{x}$ is a specific store;

- $\quad \mathrm{j}$ is the number of products (SKUs) at store $\mathrm{x}$, where $\mathrm{y}$ is a specific SKU at store $\mathrm{x}$;

- $\mathrm{k}$ is the probability distribution for selling SKU $\mathrm{y}$ at store $\mathrm{x}$;

The objective is to maximise the channel profit by stocking inventory that is the most likely to sell for the most profit. This objective function is defined as:

$f: \operatorname{maximise}(\mathrm{P})$

Profit is calculated by taking the total value of sales of all products and deducting all costs associated with those products.

$\mathrm{P}=\mathrm{I}-\mathrm{C}-\mathrm{O}-\mathrm{H}$

Income is the sum of all products sold at all stores multiplied by the probability of selling each product.

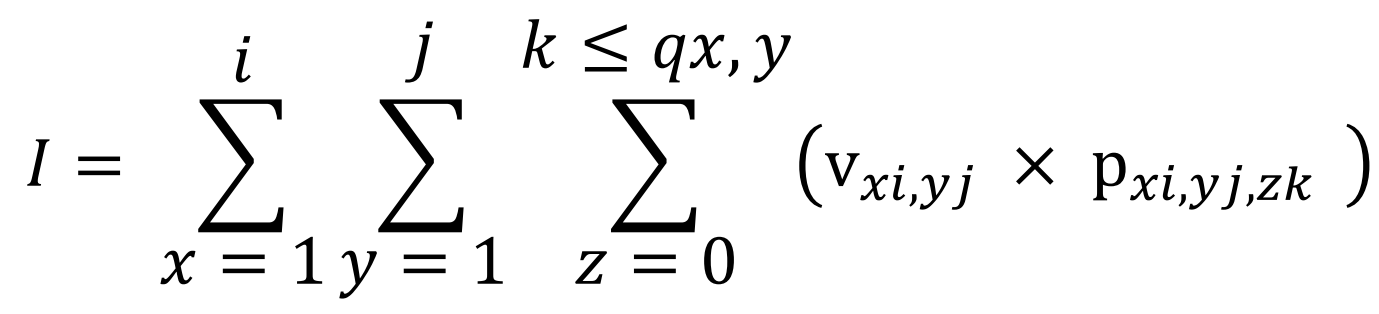


Cost of Goods Sold (COGS) is the cost to purchase, warehouse and ship all products to all stores

$$
C=\sum_{x=1}^{i} \sum_{y=1}^{j}\left(\mathrm{~m}_{x i, y j}+\mathrm{c}_{x}\right) \times \mathrm{q}_{x, y}
$$

Obsolescence cost represents the risk that a product never sells and must be written off, the obsolescence risk increases over time as the product nears its end of life. For this model, the obsolescence risk is a static percentage for each product. The Obsolesce cost is calculated by summing all product multiplied by the cost and multiplied by the obsolescence risk.

$$
O=\sum_{x=1}^{i} \sum_{y=1}^{j} \sum_{\substack{\left.z=0 \\-\mathrm{p}_{x i, y j, z k}\right)}}^{k \leq q x, y}\left(\left(\mathrm{~m}_{x i, y j}+\mathrm{c}_{x}\right) \times \mathrm{o}_{x} \times(1\right.
$$

The holding cost represents the undesirability of not selling a product and leaving that product on the shelves in retailers stores. This undesirability is represented as a dollar amount per product per day and equates to wasted resources. The total holding cost is calculated by summing up the multiplication of the probability a product won't sell by the product holding cost.

$$
H=\sum_{x=1}^{i} \sum_{y=1}^{j} \sum_{z=0}^{k \leq q x, y}\left(\mathrm{~h}_{x} \times\left(1-\mathrm{p}_{x i, y j, z k}\right)\right)
$$

The optimal inventory levels are subject to constraints, the first being a limitation on the total cost of goods in the channel that the MMR can maintain (referred to as Budget), this is a single value for all products at all stores. The purpose of this constraint is to reflect the fact that MMRs are constrained by available cash and will be unwilling to exceed a target amount in terms of cost of goods.

The second constraint is availability which is a representation of the customers satisfaction with the retailer. Should a customer walk into a retail store with the intent of buying a product and that product is not available the customers satisfaction with the MMR is diminished. Availability is a calculation of total demand fulfilled / total demand, and a minimum availability level is targeted to ensure that unhappy customers due to lost sales are minimised. Demand is determined by taking the probability of selling the nth item of a product at a store, if the probability is greater than or equal to 
0.5 then that product is in demand and not stocking the nth product will result in a reduction in the overall availability score.

The third constraint is implemented to ensure that the MMR profit to cost ratio is commercially viable. That is, the rates of return for the costs incurred should not fall below a certain threshold. The margins for the top tier of mobile phones is generally very low $(<5 \%)$ however it is worth noting that retailers benefit through the sales of devices in other ways, such as the sale of accessories or by receiving subsidisation from the Telco.

The constraints are defined as:

$$
B \leq C
$$

And

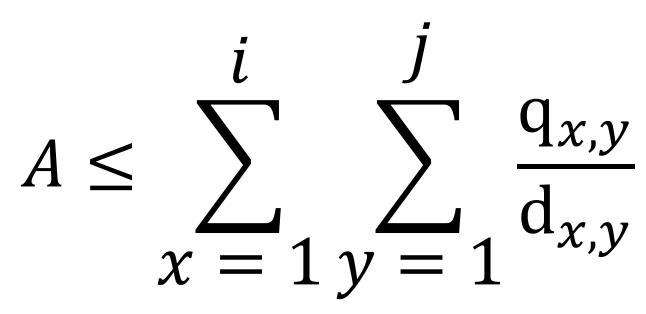

(8)

And

$$
R \leq(C-O-H) / P
$$

Where $x=\{1,2, . . i\}$ and $y=\{1,2, . . j\}$ and $z=\{1,2, . . k\}$

Equation (1) thru to (6) are the objective functions while equations (7), (8) and (9) are the constraints. The decision variable is the integer value representing the quantity of each SKU at each store.

An admissible heuristic has been implemented for validating the results of each metaheuristic. The heuristic can be applied to a single dimension to determine the maximum possible profitability of an individual dimension. It can also be applied to all dimensions, by aggregating the total al all individual dimensions. The heuristic is formula (2) without any constraints applied.

\section{Treatment of the Data}

The data applied to the models in this paper represents the distribution of mobile phones to a telecom retail channel. The data has been completely obfuscated with all values being altered from their original values, a set of rules were provided by company representatives that ensured the obfuscated data is still within realistic ranges. 50 stores and 30 SKUs providing 1500 unique combinations form the data set, with the following rules being applied to generate the data set: 
Margin: a random number between 5 and 50, applied to each SKU;

Cost: a random number between 50 and 100, applied to each SKU;

Holding cost: a random number between 0.5 and 1.5 (representing the holding cost of 1 item per day), applied to each store;

Obsolesce Risk: $20 \%$ of all SKUs (6) have a obsolesce risk, of which the risk is a random percentage of either $10,20,30,40$ or 50 ;

Sell Thru: Stores can sell on average 20-200 sales a week and typically the bigger profile stores will consistently sell larger volumes. A single SKU at a store would not often sell much more than 10 units a day. An exception to this rule is product launches which are not considered within the data set;

The above rules generate a data set that equates to a problem with $3 \times 10^{35}$ estimated possible solutions.

For this data set, the following constraint related parameters apply:

- The total cost of all product should not exceed 2,000,000 AUD;

- The availability in the channel should exceed $95 \%$.

- The profit to cost ratio should exceed 5\%;

As discussed further in this paper, these constraints are soft targets and penalties are applied if these parameters are exceeded. A rate of 500 AUD is applied for every $1 \%$ deviation from a target.

\section{Approach to solving the problem}

The approach adopted in this paper to solve the above optimisation problem is to separately apply three local search metaheuristics and compare their implementations and results. Figure 2 - VMI Implementation shows how the VMI model shown in Figure 1 - VMI Model has been implemented technically. The process is described as follows:

Step 1. The quantity of sales by day of each SKU at each store is imported (sell thru) and an average and standard deviation are calculated for each SKU at each store from the sell thru;

Step 2. A normal probability distribution is created using the average and standard deviations for each SKU at each store (described in more detail in Forecasting methodology;

Step 3. Data used to calculate candidate fitness such as cost, and margin are imported for each SKU and store combination along with the $\mathrm{SOH}$ already in the retail channel.

Step 4. An admissible heuristic is calculated that provides a theoretical optimal result not considering constraints.

Step 5. User defined parameter values (such as mutation rate) are applied to the selected metaheuristic;

Step 6. The selected metaheuristic is run;

Step 7. The results of the metaheuristic are output to a file; 


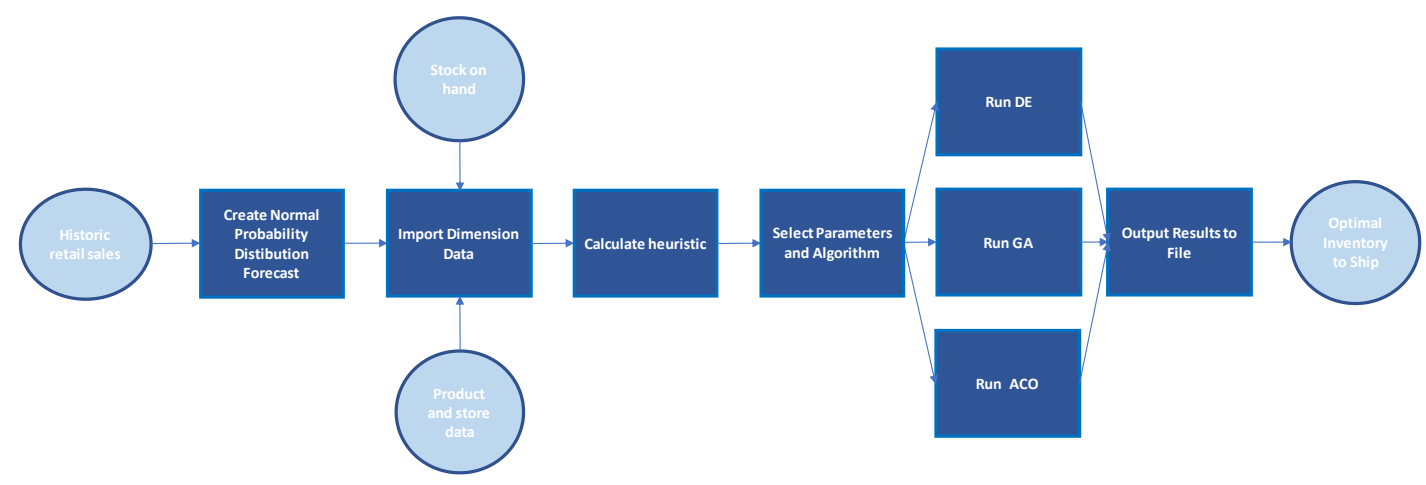

Figure 2 - VMI Implementation

The problem to be solved is a single objective optimisation problem with the objective of finding the correct quantity for each store and SKU combination that is the most profitable. Each store and SKU combination are dimensions with the quantity the value of each dimension. Each dimension has a probability distribution of possible quantities that may be viable for that dimension. The probability relates to the likelihood that the store will sell at least $n$ of that product, and this probability is only used in calculating the fitness of a candidate (profitability).

\section{APPLICATION}

This section details the implementation of each of the algorithms required to address the problem. In each case the implementation follows the approaches defined in 2. REVIEW OF THE RELATED LITERATURE with only deviations from the norm or structures specific to the problem being defined here.

\section{Common Algorithms}

As shown in Figure 2 - VMI Implementation, each Algorithm shares a common platform before the metaheuristic specific component is executed, this following section describes the common steps.

\section{Dimension Limits}

For all algorithms it is important to note that the "limits" of each dimension are specific to that dimension, the lower limit will always be 0 . The upper limit is the discrete quantity where the cumulative probability to sell exactly $n$ is $>=5 \%$ and the cumulative probability to sell exactly $n+1<$ $5 \%$. Each metaheuristic is designed so that it will never select a quantity outside of these limits, regardless of the operation performed on it (ie mutation, crossover). This significantly reduces the size of the search space compared to an implementation that only applies a single global limit.

\section{Parameter Tuning}

The following parameter tuning mechanics were applied to each of the three algorithms in the following manner. First, arbitrary parameters values are chosen with population being set to 10 , the metaheuristic in question is run 30 times and the best candidate's fitness of each execution is averaged across all executions to determine the average fitness, the same is applied to the generation the best candidate was found, along with the generation the population stagnated. This is repeated with the population being increased in increments of 10 up to 200. the smallest population value that yields the best set of averages becomes the tuned value for population. The best average is applied using the following logic: The highest average fitness is chosen, if there are population values with equal fitness then the population that yields the lowest average generation found, if there are population values with equal average generations found then the population that yields the lowest average 
stagnation generation is chosen. Finally, if there remain multiple populations that are the best fit, then the population found first is chosen (ie the smallest population).

The chosen population is then set as the population size parameter and then the parameter with the most relevance is then tuned using the same process. The specifics of each metaheuristics are as follows:

- For GA's the next parameter is mutation rate which is incremented from 0 to 1 in steps of 0.05 ;

- For ACO the next parameter is evaporation rate which is incremented from 0 to 1 in steps of 0.05 , followed by heuristic weight which is incremented from 0 to 10 in steps of 1 , followed by the parameter that determines the likelihood that the highest probability options is chosen (regardless of probability, which is incremented from 0 to 1 in steps of 0.05 ;

- For DE's the next parameter is mutation rate which is incremented from 0 to 1 in steps of 0.05 , followed by scale factor which is incremented from 0 to 1 in steps of 0.05 ;

The above methodology was not successful in tuning parameters for the metaheuristics, the reasons for this were three-fold. Firstly, the time to execute these tuning mechanisms was significant and prohibitive with the hardware available. Secondly, the ranges and steps provided did not provide complete enough coverage of all parameter combinations. And thirdly, there was no patterns that identified when cycling thru the parameter combinations that were able to provide intuition as to what optimal combinations might be. Given this lack of success, the author has turned to literature to help advise reasonable parameters settings (where available).

\section{Population Size}

It is understood that a larger population can improve the outcome of a GA but also may take a population longer to converge (Rylander, 2002). The business needs in this instance was to have confidence that the model would reliably find the optimal (or near optimal) solution without exceeding 1 hour of runtime. Large to extremely large population sizes violate this requirement and thus there was a need to find an appropriate population level that strikes balance between solution quality and solution speed.

The first attempt (described in the parameter tuning section above) was unsuccessful, which led to the second approach which was to consider the literature and attempt to validate if literature proposed population sizes would be appropriate, this was attempted for a single metaheuristic, DE. The literature regarding DE populations sizes was considered - a rule of thumb for DE populations is given as $10 x$ the number of dimensions by (Price, 2005). While DE (Chen, Montgomery, \& BoluféRöhler, 2015) concludes to have at least $n>d$ for significantly high number of dimensions.

The number of dimensions for this dataset is 1500 and to attempt to determine an appropriate population for the given model the DE model has been executed two times, one with a population of 50 and one with the population of $2000(n>d)$. For a population of 2000, that maximum profitability found over 10 iterations (of 5000 generations each) was 47200.72 found after 9996354 candidates. Compared to the equivalent execution with a population of 50 resulted in a maximum score of 46265.3004 found after 249861 candidates. A very marginal quality improvement was the result at approximately $4 \mathrm{x}$ the cost in terms of candidates. Computation was not formally recorded however it can be confirmed that it was at least an order of magnitude more to run the metaheuristic with a population of 2000. Thru this process it was empirically determined that the population of 2000 offered no justifiable improvement over the population of 50 for the DE metaheuristic.

The final decision was made to set the populations for all three metaheuristics to 50 considering the lack of any clear evidence from the other methods investigated. 
Penalty Functions

Penalty Functions are a method of applying constraints to search optimisation techniques, and were the methods primarily considered during this paper. An alternative to penalties is to consider the penalties as objectives in their own right (Vieira, Adriano, Vasconcelos, \& Krahenbuhl, 2004).

Hard constraints are constraints that cannot be breached and any candidate solution that breaches a hard constraint is considered infeasible. This research attempted to implement the death penalty for hard constraints, regardless of the generation number. The implication of this constraint method is that it eliminates all these infeasible candidates from consideration and experimentation showed that it reduced the effectiveness of the ACO metaheuristic. A further issue identified with the death penalty is in scenario's where candidates that triggered a death penalty in the first generation could not be selected for reproduction because they had no chance of being selected as a parent. Furthermore, candidates that had triggered the death penalty could not be removed from the initial population without risking a drop-in population numbers that would fall below the minimum needed to reproduce. In subsequent generations, this is not an issue, because children with 0 scores will never succeed their parents.

The impact of the death penalty was so severe on the performance of the ACO metaheuristics that soft constraints were implemented (under consultation with the business) for each of the constraints, removing the death penalty entirely from all metaheuristics.

Soft constraints are constraints that can be breached and thus a candidate solution breaching a soft constraint can still be feasible however they are still considered suboptimal. To reflect this suboptimality a penalty function can be applied to the fitness score of the candidate. Penalty function methodologies described by (Michalewicz, 1995) (Yeniay, 2005) and the Violation Constraint-Handling (VCH) method applied by (Chehouri, Younes, Perron, \& Ilinca, 2016) were considered. This research paper implements a very basic static penalty where the percentage of deviation from the constraint is multiplied by a static parameter and deducted from the fitness score.

The author acknowledges that the simplistic penalty policy selection has been made without consideration to the efficiency of the implemented models and that there could well be room to improve these models by making a better-informed penalty policy decision. The key concern that is addressed, is that the models all implement the exact same penalty policy ensuring that the penalty function is not a parameter that could cause variance between the different metaheuristics.

The amount of penalty rate applied was an amount approximate to the calculated heuristic value of the data set, in this case 50,000 . le. If a single constraint was breached by $100 \%$ then approximately the maximum possible score would be deducted.

\section{Execution Time}

Note that for as this experiment is a real business problem execution time was the preferred output over CPU cycles.

Candidate Evaluation

The fitness of each candidate is calculated by an implementation of the formula described in section 4. 


\section{Genetic algorithms (GA)}

A GA model was created following the pseudocode described in Section 2 - Genetic Algorithms, with the following implementation specific constructs:

\section{Problem Representation}

The GA population is made up of individuals each with their own genetic configuration. This genetic information is represented within a chromosome made up of a set of genes. All individuals in the population have the same chromosome configuration with the same set of genes. The only thing that differs between individuals are their alleles, which are the values each of the genes take. Each have a common set of dimensions which is represented as the chromosome. A single dimension is represented as a gene and consists of the unique store and SKU combination along with a set of quantities and the related probability that the responding quantity will sell. Finally, the value (allele) that is held within a gene for a specific is the quantity of SKU to ship to that specific store along with its probability to sell.

\section{Population Size}

The population undulates in size throughout each generation but returns to a consistent population size between generations. Within a generation the population $(n)$ grows and contracts, in an example where $n=50$ the population size follows the following process: Half the population $(50 / 2=25)$ are selected as eligible parents, however the population is still 50 because it contains the ineligible parents; Each eligible parent mates twice $(25 * 2=50$ children and total population of 100$)$; Each child is compared with one each of the parents and the weakest is discarded from the population 100/2 = $50)$;

\section{Parent Selection}

Roulette wheel sampling is applied during parent selection by having each candidate in the population be weighted on their fitness (as a percentage of population fitness) and then randomly choosing a parent from all available candidates (not yet selected as parents) weighted by their fitness. Candidates with higher fitness have a higher probability to be selected as parents than those with a lower fitness score.

Parents with negative scores are problematic to this selection method and are never selected. However, it is possible for the best possible score to be a negative score - which means this method is not robust for such scenarios. An improvement could include the normalisation of all scores to be positive.

\section{Mate Selection}

Mate selection is the process of determining how parents are paired off with one another. In this implementation it is performed randomly among the parents with each selected parent mating with 2 other distinct parents.

\section{Crossover}

For discrete integer-based problems, there are several methods for representing chromosomes. 1) Convert the genes from integer to binary and store them in a vector of binary digits. 2) Convert the integers to a single vector of single digit integers. In both cases (1) and (2) the maximum possible magnitude of each gene must be known and encoded with preceding 0 's if the gene is of smaller magnitude otherwise it will be difficult to decode the vectored chromosome. 3 ) Leave the integers as they are and put them in a vector as is. 
Crossover (finding a random point along the chromosome) has a different application and effect in each of these 3 mechanics. In options (1) and (2), crossing over at any point introduces the possibility of crossing over the gene itself (a form of mutation) - resulting in a new and different kind of gene. In option (3) the gene can never be crossed over, so the children will only ever have genes that are a subset of their parents.

Option (3) has been chosen for this implementation and a mechanism is incorporate to simulate the possibility that a gene may be spliced during crossover. The mechanism is to stochastically determine if the crossover occurs between genes or between a gene, should it be between a gene then a new value is stochastically chosen (of any valid value within the limits of that dimension) for the gene at the crossover point (with no weighting applied to each possible value).

The result of this mechanism is behaviour like binary crossover (described in option (1)) however it is of note that the behaviour is not identical and output from an implementation of (1) and (3) would differ. Speculation suggest that the binary It is beyond the scope of this paper to understand what the impact may be; however speculation is that adopting option (3) over option (1) sacrifices a degree of implicit parallelism (Holland, 1984)).

\section{Mutation}

The set of newly created children have a possibility of mutating which is determined by dividing the mutate parameter by the number of dimensions for each candidate and stochastically determining if the resultant value triggers a mutation. If a dimension of a candidate does mutate, the dimension value is updated with a new value randomly selected (without any weighting) from all possible values for that dimension.

\section{Candidate Selection}

Tournament selection is applied to determine which candidates remain for the future generation. Each child (in the order they were created) is compared to only one of the candidates in the original generation (in the order they were created). The candidate (original generation or child) with the highest fitness score survives to the next generation. There may be potential issues with ordering the children and parents by age and competing against one other, and alternative approach would be to randomise their orders.

\section{Stagnation / Convergence}

Stagnation or Convergence (Zhou \& Harris, 2008) occurs if the populations average fitness remains the same for 5 generations, in which case the algorithm terminates. The rationale behind this choice is that if the average population score remains the same it means that not a single child created from the population is an improvement from any parent. For this to occur for 5 consecutive generations implies that there is very little likelihood that further improvements will be found.

\section{Ant Colony Optimization (ACO)}

An ACO model was created by applying Dorigo's Ant System (AS) approach (Dorigo \& Gambardella, 1997). It follows the pseudocode described in Section 2 - Ant Colony Optimization, with the following implementation specific constructs:

\section{Problem Representation}

In ACO the population is a colony of individuals ant that each have memory of the tour they have just taken. While this terminology is abstractly different to GAs, in practice the data structures implemented remain the same, with a few key additions. Additional to ACO is a global pheromone matrix that each ant is aware of when making decisions on which route to traverse. The pheromone matrix is the list of all possible combinations of SKU, store, quantity and probability to sell with pheromone deposits for each combination. 
Each generation, when each ant completes a tour it lays pheromone on the path they took to complete the tour. The amount of pheromone they deposit is inversely proportional to the length of the tour just taken (see the Section of Pheromone Update). In the VMI problem a single leg in the tour is a single dimension and the tour is all dimensions (Store and SKU combination). At each leg of the tour, the ant stochastically decides which quantity should be shipped for that store and SKU (see Route Selection). This process is repeated for each leg of the tour/dimension until each dimension is traversed and the tour is complete. Each ant then lays its pheromone and the process is repeated.

\section{Route Selection}

Each dimension has multiple valid quantities and each of these has a "edge probability" which is the likelihood that a candidate/ant will select (traverse) that quantity. The edge probability is calculated using the formula below:

Edge Pheromone *1/|(Probability to sell quantity j for store/SKU combination * SKU Margin) - SKU holding cost $-\left(\left(\text { SKU Cost * Obsolesce Risk }{ }^{*}(1 \text { - Probability to sell quantity j })\right) \mid\right)^{\wedge} \beta$

/

$\Sigma$ all Edge Pheromone * (1/I (Probability to sell quantity $\mathrm{j}$ for store/SKU combination * SKU Margin) SKU holding cost $-\left((\text { SKU Cost * Obsolesce Risk })^{*}(1-\right.$ Probability to sell quantity $\left.\left.\mathrm{j})\right) \mid\right)^{\wedge} \beta$

Where $\beta$ is a parameter that determines the relative importance of pheromone versus distance (as per (Dorigo \& Gambardella, 1997)).

\section{ACO and Death Penalties}

An issue with applying a weight desirability where death penalties are implemented is that the algorithm will continue to select maximum quantities (they return the highest fitness) but then they breach hard constraints and are set to 0 . Leaving a population with a lot of 0 score candidates. This severely damages the algorithms ability to converge. This was a key factor in deciding to remove all death penalties and replace them with soft constraint penalty functions.

\section{Pheromone Update}

Once a candidate has traversed each dimension (and selected a quantity at each) pheromones are added to that dimension value to increase its desirability for selection by subsequent generations. The increase in pheromone is calculate by $1 /((1+$ heuristic) - tour_score) where the tour_score is the total profit of the candidate. This translates to 1 divided by the candidate's distance from optimal, in other words, the further the distance, the lower the amount of pheromone deposited. The plus one is a precaution to prevent divide by zero errors if the tour_score equals the heuristic.

\section{Best Tour}

A best tour function was initial implemented but then discarded as the results indicated it was not contributing any value to the ACO search. The best tour function similar as that a concept described in the Ant Colony System (ACS) where the ant with the most successful tour so far applies a global updating rule (Dorigo \& Gambardella, 1997). A variation on this concept was attempted in this model - which is that rather than just adding pheromone to the best tour, additional pheromone is added by the best tour (on top of the pheromone added by all ants) to further encourage subsequent candidates to pursue the best tour. This best tour pheromone increase is calculated by: best_tour_bonus / ( $(1+$ heuristic) - tour_score) where the best_tour_bonus is a static value that has the effect of adding a significant increase (depending on its magnitude) to the pheromone deposited. As a candidate finds a solution that is closer to the optimal, the value of pheromone deposited by the best_tour_bonus will increase. It is important to find a best_tour_bonus value that has a relative influence on the pheromone update. For this implementation, the best_tour_bonus is 
set to the value of the heuristic +1 , which means the maximum value of pheromone that could be deposited by the best tour is 1 .

This hybrid approach to Ant system (AS) and Ant Colony System (ACS) was adopted to attempt to strike a balance between exploration and exploitation however through empirical testing no advantage was identified so the functionality was removed and AS was adopted by default.

\section{Pheromone Evaporation}

Pheromones evaporate over time to ensure that the more generations that occur since the pheromone was laid the less significance that result has, or in other words the more recent the result the more significant it is. This is achieved with the following calculation: (1- evaporation_rate) * pheromone, where the evaporation rate is a value between 0 and 1 that is determined empirically during parameter tuning.

\section{Stagnation/Convergence}

For ACO convergence occurs when $n \%$ of ants are following the same route (Meyer, 2004b). The rationale behind this is that it is unnecessary to increase the pheromone on the optimal track to such an extent that it effectively eliminates the chance that candidates will probabilistically select any other path. Furthermore, depending on the parameter tuning it may not be possible to achieve this (ie. If the rate of pheromone evaporation eliminates any potential pheromone gains, even if all ants are traversing the optimal path).

\section{Differential Evolution (DE)}

A DE model was created following the pseudocode described in Section 2 -Differential Evolution, with the following implementation specific constructs:

\section{Problem Representation}

Abstractly, DE is identical to the GA in problem representation as it used the same concepts of genetics to explain the problem (Refer to Genetic Algorithms (GA) - Problem Representation). The main challenge faced when implementing DE's is that they are innately continuous and the VMI problem deals specifically with discrete decision variables. Therefor a mechanism to adapt the DE metaheuristic to a discrete solution was required.

\section{Implementation of a Discrete DE Model}

If we consider an example where each candidate has 2 dimensions, and $x$ and $y$ coordinate. In this example we will apply the mechanics of $D E$ to a single candidate for a single generation to illustrate the advantage continuous variables have over discrete variables. Given some arbitrary vectors, Candidate $A$ has a vector of 2.37,4.15; Candidate B has a vector of 2.35, 3.81; and Candidate $C$ has a vector of 2.42, 4.33; and simulated a single differential evolution on candidate A, Candidate A's resultant vector will be $(2.37,4.15)+=(2.35,3.81)-(2.42,4.33)=(2.30,4.33)$; What is shown through this single iteration is that Candidate A's vector is perturbed minimally and as a population converges the amount of perturbation reduces over time. When compared to a discrete model with the following vectors: Candidate $A$ has a vector of 2,1; Candidate $B$ has a vector of 1,4 ; and Candidate $C$ has a vector of 4,3 ; the resultant vector is $(-1,3)$, this poses two problems the first of which is that negative dimensions in the VMI problem are nonsensical (you cannot have a negative quantity of stock) and yield invalid fitness scores the second problem is that the dimension values tend to overshoot optimal values (this was observed during experimentation) and never optimise.

For example a dimension that could have a possible value between $0 . .7$ has 7 discrete values that the decision variable can be assigned. Applying $D E$ often yields a result that is outside the range of $0 . .7$. To describe this scenario, we will consider Store A with SKU B where the possible quantity could be any value between 0 and 7. Again we consider 3 candidates to which the DE mechanics will be applied. 
Candidate $A$ has a value of 2, Candidate $B$ has a value of 4 and Candidate $C$ has a value of 7; The resultant value is $2+=4-7=-1$, as -1 is outside the limits of valid values.

This above scenario along with the fact that steps are relatively large causes candidates to jump around the dimension values and the step size (in subsequent generations) does not reduce over time. These two problems generally make native DE unsuitable for this VMI problem.

To adapt the DE metaheuristic to suit this VMI problem a variation on the DE model has been applied. Firstly, perturbation is bounded by the limits of the dimension values, ie. The dimension example above cannot exceed 7 or fall below 0 . Should the result of a perturbation fall outside of the limits the candidate is perturbed to the limit, which is either 0 or 7 . Secondly, a scale factor is applied to determine the size of the perturbation and is described in the following section.

Scale Factor

To mitigate the impact of candidate solutions jumping around the dimension space and not having step side reducing overtime a new parameter is considered. The scale factor is applied as a coefficient to reducing the discrete step size to do this a normalised range of $0 . .1$ is mapped to the range of 1 to step size. A scale factor of 1 will yield a full step size, where as a scale size of 0 will yield a step size of 1 (the smallest possible discrete increment/decrement). The scale factor is only applied when a perturbation has taken place (ie. a step size of 0 will not have the scale factor applied). The resultant mechanism provides a lever to throttle the step sizes, the studies conducted attempted to find an optimal scale factor for this implementation.

Of further note, a dynamic scale factor may have yielded a better performance (ie. dynamically Increase the degree of throttling over the course of multiple generations but was not applied in this study.

\section{Forced Perturbation}

Candidates in a DE population have only a single mechanism to perturb their position in the search space which is through the DE mutation mechanism. This means, having a candidate that fails to mutate offers no value, which led to the forced perturbation being implemented in the algorithm. Should a candidate fail to mutate a single dimension then the candidate will be rolled again until at least one mutation of a dimension occurs.

\section{EXPERIMENTAL RESULTS}

\section{Computational results}

The three models have been developed using Java 8 and all models have been executed on a 64-bit Windows PC with an Intel ${ }^{\circledR}$ Core $^{\mathrm{TM}}$ i7-6600U CPU @ 2.60G Hz 2.81G Gz with 16.0 GB RAM.

\section{Simple Heuristic Search}

To compare the suitability of each Al approach a baseline has been created in the form of a simple heuristic (SH) search. The $\mathrm{SH}$ search is a straightforward heuristic that could be described as a reverse breadth first search which pops a single randomised node into the frontier at a time. It starts by maximising the quantity of each dimension. Knowledge of the problem domain provides insight that for this data set, the near optimal solutions are significantly closer to maximum quantities as opposed to the minimum quantities, which ensures a much quicker convergence. It is worth noting, that a different data set may not be the case and it would be a more difficult task to create an all-purpose simple heuristic search that also leverages domain knowledge.

Starting with a candidate with the maximum possible quantity for each dimension the heuristic first clones the candidate and randomly choses one dimension from the clone (of the 1500) and 
decrements it by one. The original and the clone are compared to each other and if the clone is an improvement over the original, it is retained. To compare the $\mathrm{SH}$ and the Al metaheuristics more evenly, the $\mathrm{SH}$ is initialised with the same number of candidates in its population (50). This process is repeated for 5000 generations or until the population stagnates (ie no. single candidate improves after 5 generations).

The SH search has a slow and steady convergence pattern and due to the initial population violating a large amount of constraint, begins with a negative score. The observation from the SH search is that the rate of improvement in score decreases over time in other words effort spent searching returns consistently diminishing returns over time.

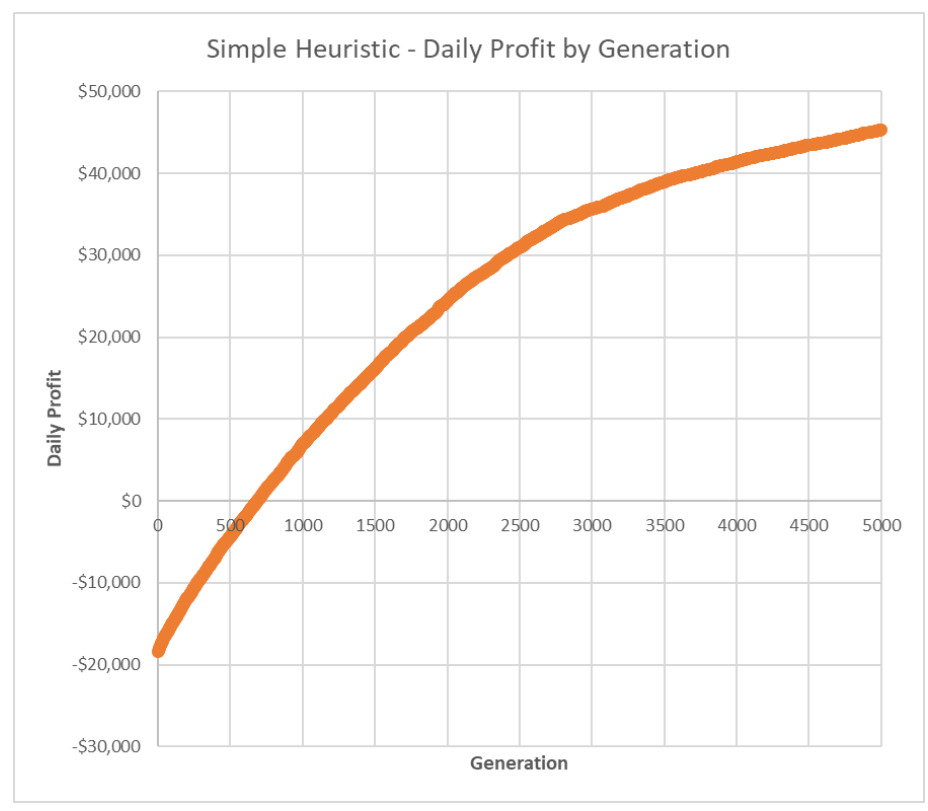

Figure 3 - Improvement in profit over generations for the SH search

A reverse SH search was implemented to confirm that its performance would be inferior. Figure 4 Improvement in profit over generations for the reverse SH search, demonstrates that while the heuristic does not start off as disadvantaged, its performance (in terms of solution quality) is an order of magnitude less than its predecessor.

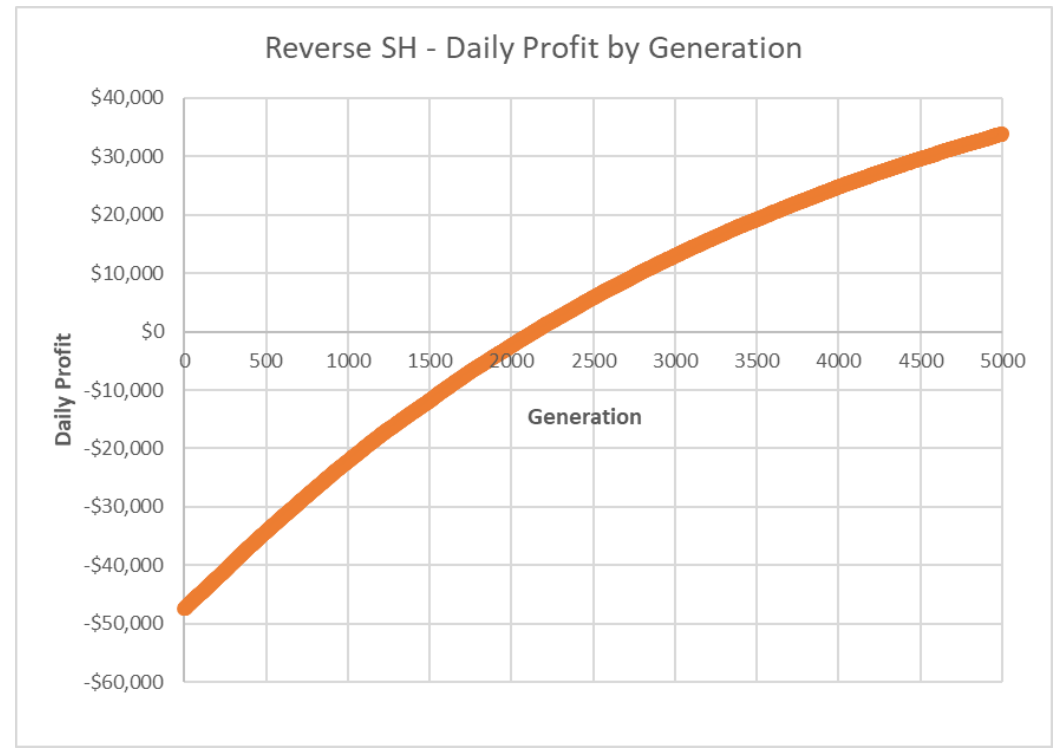

Figure 4 - Improvement in profit over generations for the reverse SH search 
Parameters used

The following parameters have been used for the execution of the metaheuristics:

Table 2 - Parameters Used

\begin{tabular}{|c|c|c|c|}
\hline Metaheuristic & Parameter & Description & Value \\
\hline ALL & POP_SIZE & $\begin{array}{l}\text { Number of candidates each } \\
\text { generation }\end{array}$ & 50 \\
\hline ALL & MAX_GENERATIONS & $\begin{array}{l}\text { Maximum generations permitted (if } \\
\text { metaheuristic does not converge } \\
\text { prior) }\end{array}$ & 5000 \\
\hline ALL & NO_MODEL_EXECUTIONS & $\begin{array}{l}\text { Number of iterations the search is } \\
\text { performed }\end{array}$ & 10 \\
\hline GA & GA_MUTATION_RATE & $\begin{array}{l}\text { Approximately } n \text { dimensions of } \\
1500 \text { in every candidate will mutate } \\
\text { each generation }\end{array}$ & 1 \\
\hline $\mathrm{DE}$ & DE_MUTATION_RATE & $\begin{array}{l}\text { Approximately AND at least } n \\
\text { dimensions of } 1500 \text { in every } \\
\text { candidate will mutate each } \\
\text { generation }\end{array}$ & 1 \\
\hline $\mathrm{DE}$ & DE_SCALE_FACTOR & $\begin{array}{l}\text { Coefficient for reducing the } \\
\text { discrete step size to do this a } \\
\text { normalised range of } 0 . .1 \text { is mapped } \\
\text { to the range of } 1 \text { to step size. A } \\
\text { scale factor of } 1 \text { will yield a full step } \\
\text { size, where as a scale size of } 0 \text { will } \\
\text { yield a step size of } 1 \text { (the smallest } \\
\text { possible discrete } \\
\text { increment/decrement). }\end{array}$ & 1 \\
\hline $\mathrm{ACO}$ & ACO_P_EVAP & $\begin{array}{l}\text { The pheromone evaporation rate } \\
\text { which is calculated by (1- } \\
\text { ACO_P_EVAP) * edge_pheromone }\end{array}$ & 0.1 \\
\hline ACO & ACO_WEIGHT_DESIRABILITY & $\begin{array}{l}\text { Determines the degree of influence } \\
\text { the heuristic value has on the } \\
\text { probability that an ant will select an } \\
\text { edge. Applied as an exponent to } \\
\text { the heuristic calculation. }\end{array}$ & 0.1 \\
\hline ACO & ACO_PROB_SELECT_BEST_ROUTE & $\begin{array}{l}\text { The likely hood that an ant will } \\
\text { select the most favourable edge } \\
\text { rather than probabilistically } \\
\text { selecting an edge. }\end{array}$ & 0.25 \\
\hline
\end{tabular}


Metaheuristic times

The compute time for each metaheuristic are listed in Table 3 - Metaheuristic compute times, the GA algorithm requires the least compute to calculate equivalent population and generations.

Table 3 - Metaheuristic compute times

\begin{tabular}{|l|l|l|}
\hline Metaheuristic & Instance & Time elapsed \\
\hline GA & $\begin{array}{l}\text { Pop 50, Gen 5000, Mutation } \\
\text { Rate 1 }\end{array}$ & Time elapsed: 117570 \\
\hline DE & $\begin{array}{l}\text { Pop 50, Gen 5000, Mutation } \\
\text { Rate 1, Scale Factor 1 }\end{array}$ & Time elapsed: 198842 \\
\hline ACO & $\begin{array}{l}\text { Pop 50, Gen 380, Evap Rate } \\
0.1, \text { Heuristic Weight 0.1, Prob } \\
\text { to select best route 0.25 }\end{array}$ & $\begin{array}{l}\text { Time elapsed: } 7733 \\
\text { N.B. If no convergence (ie. } \\
5000 \text { generations) then Time } \\
\text { elapsed: } 124154\end{array}$ \\
\hline SH & Pop 50, Gen 5000 & Time elapsed: 121595 \\
\hline
\end{tabular}

\section{Candidate Seeding}

Candidates for each of the three metaheuristics (not including the simple heuristic (SH)) have candidates seeded using the same algorithm. For each dimension of each candidate, a value is randomly assigned using Java 8's Random nextInt method. The seeding algorithm was executed 10,000 times and the results were plotted in Figure 5 - Seed Score Histogram, initial scores are confirmed to be approximately normally distributed according to Skewness and Kurtosis tests for normal distribution. The mean candidate seeding score is 6176 with a Standard Deviation of 2343. This is important in the following analysis because all algorithms start with the same quality candidates, with scores between -3000 and 15500 (4 standard deviations), and it is very unlikely that candidates will be seeded with scores outside of this range.

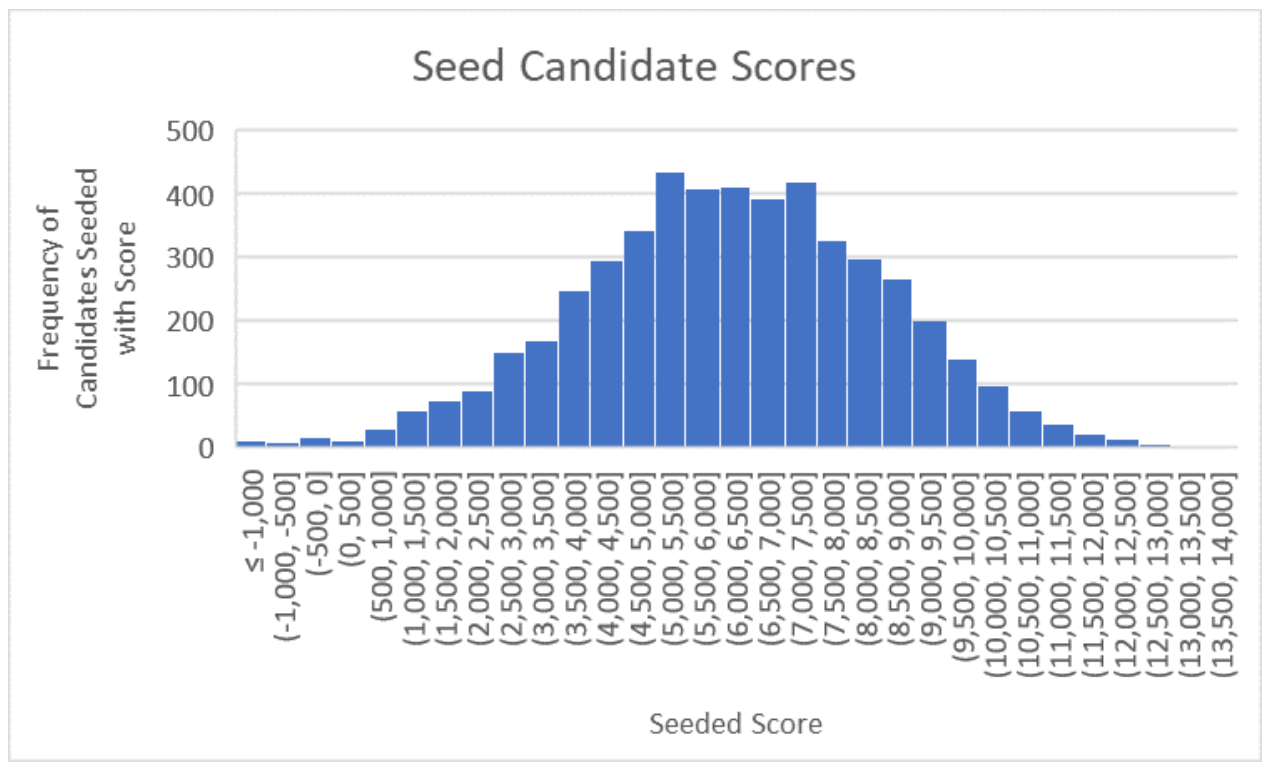

Figure 5 - Seed Score Histogram

Figure 5 - Seed Score Histogram shows the average candidate scores, however only the best candidate score (of populations of 50) are reported for the analysis of each metaheuristics. The following histogram in Figure 6 - Best Seeded Candidate Each Population (of 50), shows the likely range of the best candidate for a seed population. This is most relevant for DE and ACO as both heuristics are impacted by the best scoring candidate found. 


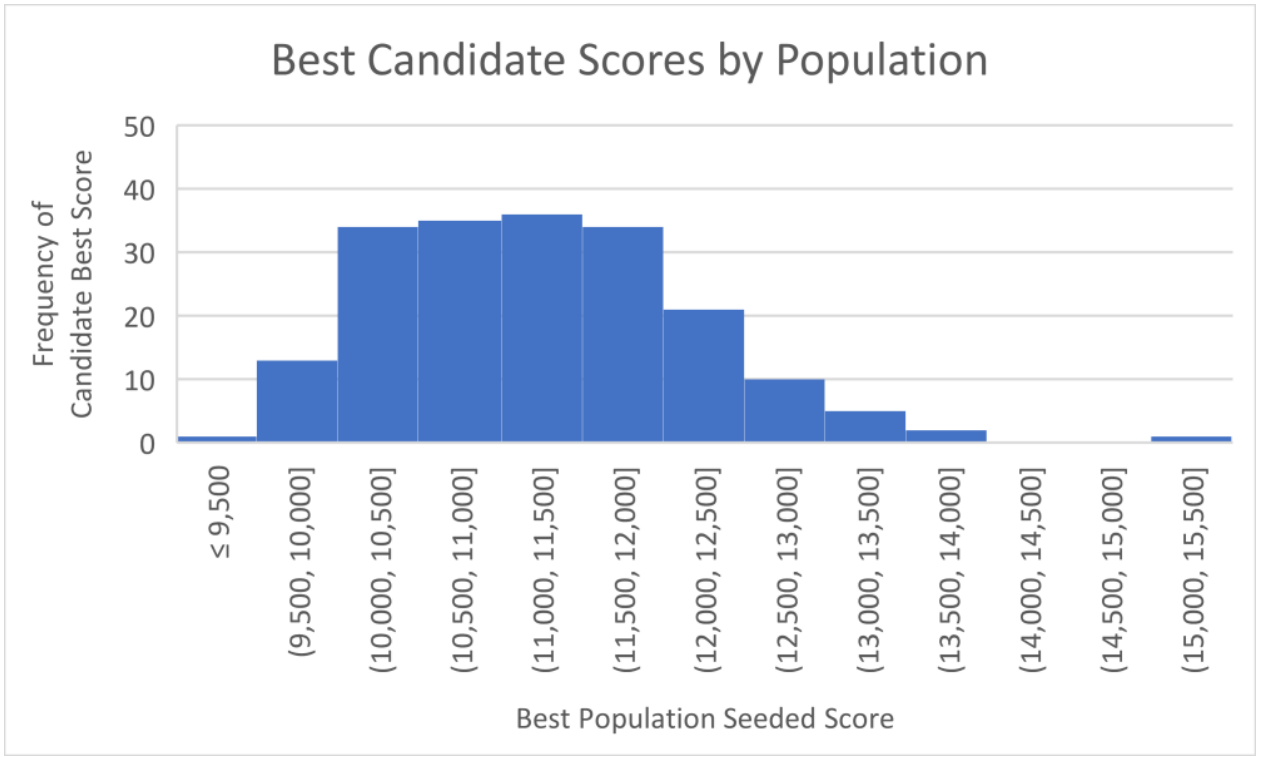

Figure 6 - Best Seeded Candidate Each Population (of 50)

The above two histograms provide us with an indicative starting position for each heuristic which we will refer to when analysing their respective convergence patterns.

\section{Results of the Genetic Algorithm}

The GA is the least complex algorithm in terms of adaption to this problem due to its generic nature and suitability for discrete problem spaces. It demonstrated several advantages over the other metaheuristics and the simple heuristic which included, being the simplest to tune due to the single parameter (mutation rate), consistently found the best solution quality by over 10K AUD, fastest to execute per generation by a small margin and it was the second fastest to converge.

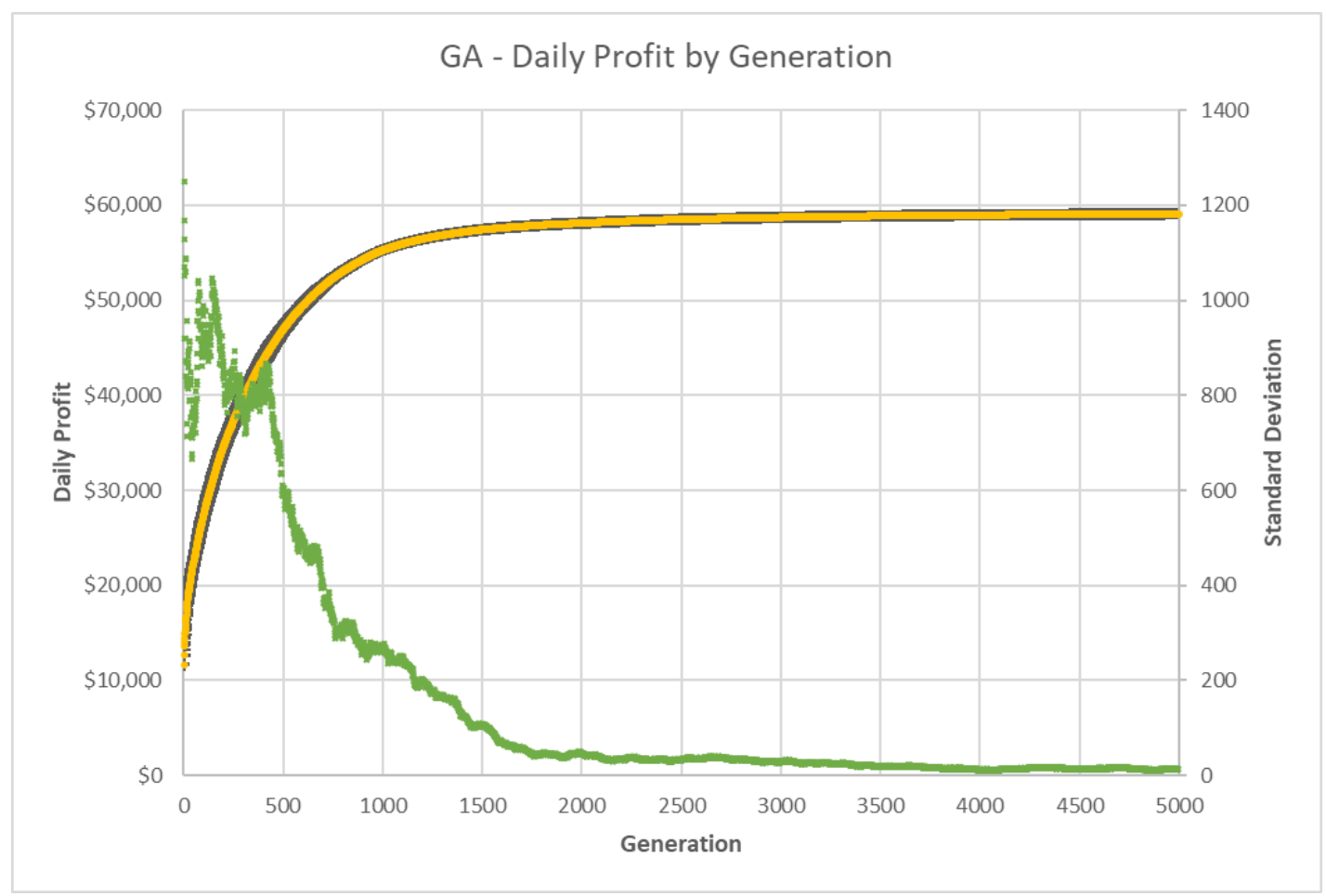

Figure 7 - Improvement in profit over generations for the GA approach 
Considering the results presented in Figure 7 - Improvement in profit over generations for the GA approach where each data point represents the "best score" for each generation. There are 10 data points at every generation, which represents the fact that 10 algorithms were executed. The yellow line represents the average of these 10 data points. The dark grey border around the yellow line shows the standard deviation of each cluster of 10 points. le. A thicker line represents a greater variance among the best candidates for each generation. The green line shows the same standard deviations on a second y-series.

The first observation is that the quality convergence was extremely consistent across executions. The consistent quality convergence can be explained as a cause of the problem definition and specifically the large range of dimensions with limited possible values for each. What we see is a problem that can only be improved by each crossover and mutation operation by predictable and limited amounts. The initial seeding is a different matter as the initial population is seeded completely randomly (at least to the extent that Java Random is truly random) and it is therefore possible to find a candidate that has a score theoretically anywhere between the minimum and maximum possible scores. The hypothesis here is that given the vast amount of permutations, it is quite likely that a highest scoring candidate is found with a score between $10 \mathrm{k}$ and $20 \mathrm{k}$ (for this specific data set) whereas it is much less likely to find a candidate with a score outside of these ranges and thus none were identified during algorithm execution. This hypothesis was tested with the results described in the candidate seeding section which confirms the likely spready of seed candidate scores. Unlike ACO, the GA experiences no "leap" in performance improvement between generations 0 and 1 , so rather generation 1 (which is the first data point in the above figure) is only marginal improved over generation 0 .

The next observation made is that the population variance decreases over time, this means that as the population approaches convergence individual diversity declines. From generation 1500 , it is hypothesised that the population becomes relatively stagnate at this point and only the high rate of mutation (every candidate approximately mutates a single dimension each generation) prevents convergence. This high rate of mutation enables each generation to make marginal gains in quality. This hypothesis can be tested by considering the actual data points for each generation and determining the distance (number of generations) between improvements in quality and the rate of improvement. The following figure shows the average gain each generation and confirms that at approximately generation 1500 only marginal gains are found each generation.

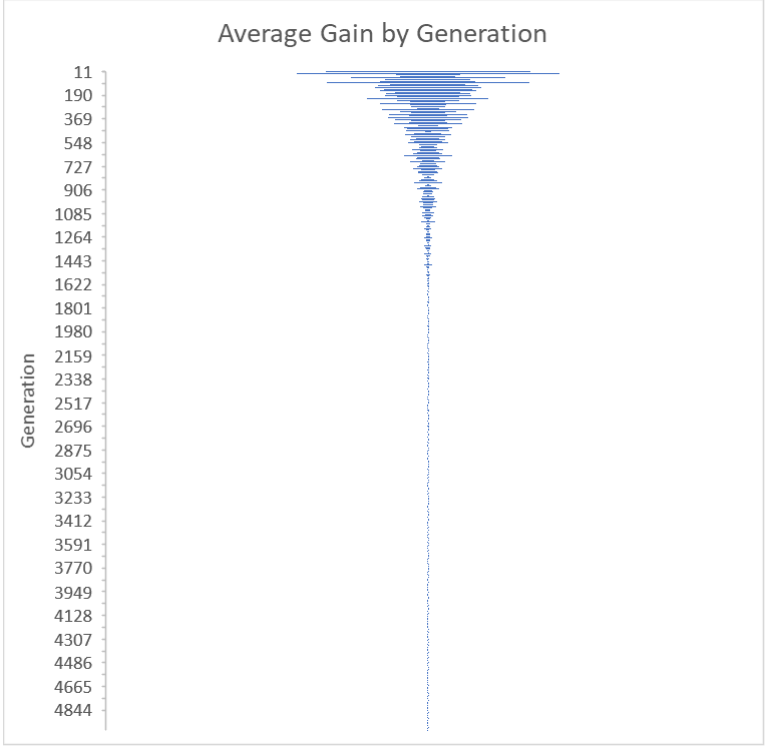

Figure 8 - Average Gains by Generation - GA 
What Figure 8 - Average Gains by Generation - GA shows is that the rate of improvement in quality between generations is due more to the size of the gains between generations and less to the frequency that gains are found. In fact, the algorithm continues to find gains consistently beyond 5000 generations, however the size of these gains is not significant. Suggesting that this data set involves a lot of combinations of data that vary in very small degrees among one another.

\section{Results for Differential Evolution}

The mechanisms implemented to attempt to adapt Differential Evolution to a discrete search problem were not successful. Arguably the DE metaheuristic is no better than the SH search as it only achieves parody in terms of solution quality with a gentler rate of quality improvement.

The specific implementation for this problem has significant short comings, in particular - candidates mutate only one of 1500 dimensions at a time, which guarantees a very slow and steady improvement over time however, experimenting with higher mutation factors did not improve the performance of the $\mathrm{SH}$ and at a certain point (approximately 50 of 1500 dimensions mutated) demonstrated that the performance declined rapidly.

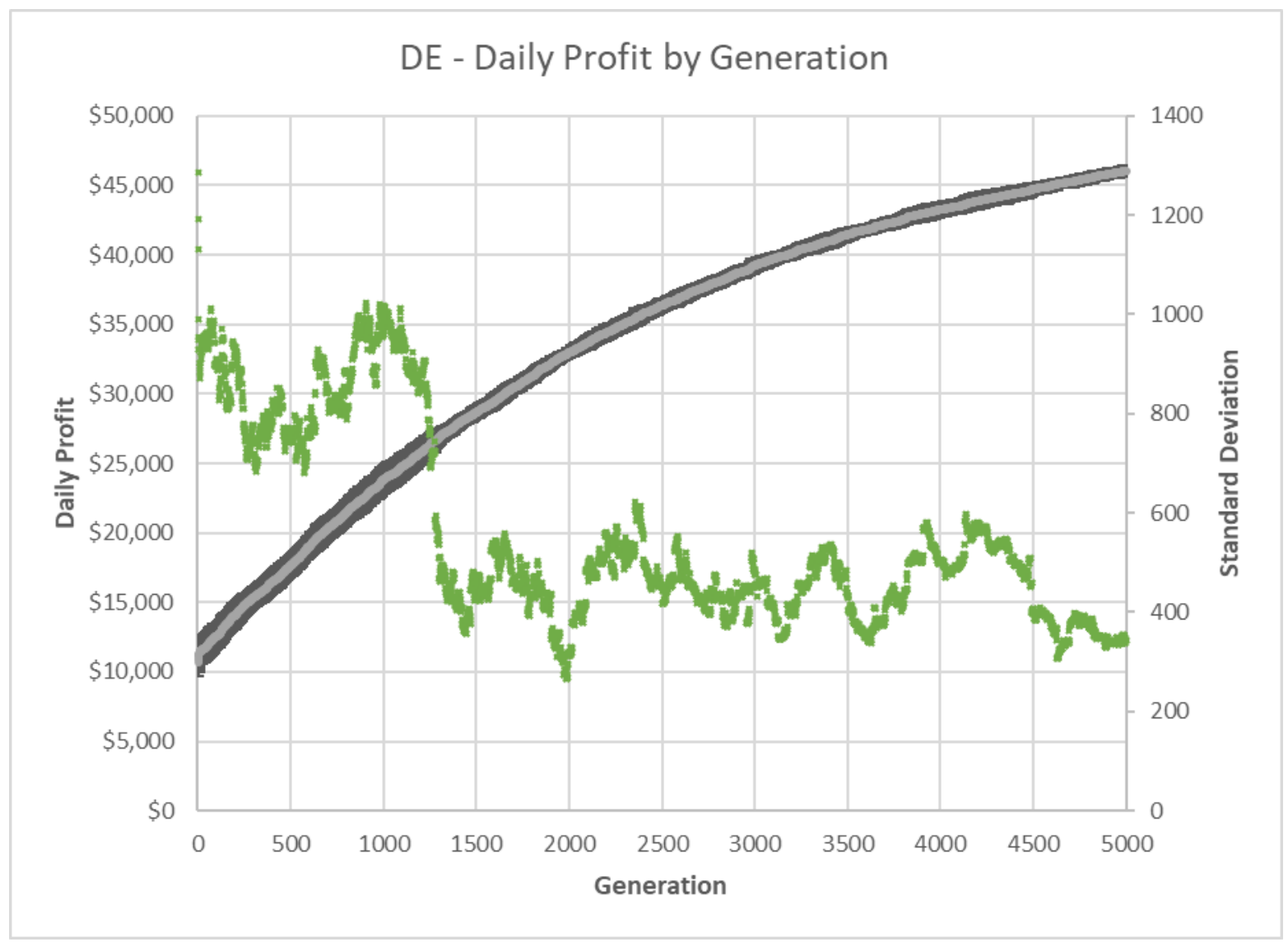

Figure 9 - Improvement in profit over generations for the DE approach

We can see by the above figure that the DE becomes gradually more inefficient at finding solution improvements over time. Arguably the rate of finding new solutions is consistent but the size in improvement of those new solutions becomes smaller as the generations progress. There are two things of interest here that possibly provide us with some insight into the problem space. The first is that there is a clear trend line with the standard deviation scatter plot, which is suggesting that there is predictability in the variance between generations. The hypothesis here is that each future population draws on the characteristics of the previous population with a low rate of mutation and so gains and losses have momentum. This theory is consistent with the GA and SH as their populations 
carry forward their genetic material between generations. ACO is the exception as ant memory is wiped between generations, and this is clearly seen in the variation of candidates having no trend between generations. The second observation is the deviation line oscillates in a roughly up and down motion. The hypothesis behind this behaviour is that the search space resembles the ocean in the sense that the deeper you go the more pressure there is and reaching new depths become harder. Therefore, it is easier for candidates in shallow waters to catch up. To test this theory the individual populations were graphed, and it validates that theory as you can see populations that drift behind, do eventually catch back up to the higher performing populations.

While these observations help to describe the problem space and confirm the fact that the DE only makes margin gains each generation (if at all) due to very small mutation rate, there does not appear to be any advantages in the DE technique over the other approaches.

\section{Results for Ant Colony Optimisation}

ACO proved difficult to find the correct parameter balance and the parameter tuning was not effective due to the number of different parameters and the uncertainty of which ranges to tune for. Suitable parameters were determined manually through empirical means however no assurance can be made over there optimality.

ACO rapidly found a sub optimal solution that while sub optimal was higher in performance quality than both the DE and SH mechanisms, it was however was 10k below the GA performance quality. This rapid improvement can be attributed to the heuristic weighting applied to each dimension variable, encouraging ants to choose values that have higher heuristic values. ACO is the only metaheuristic that encourages selection of higher performing individual values. This is described in detail as follows: Ants are strongly encouraged to selecting quantities for dimensions that are going to provide the greatest profit (but do not consider constraint penalties) so ants quickly converge on the paths that contain the highest heuristic values. These paths however are the ones that will be most heavily penalised due to constraint violations (specific for this data set). Ants will lay the most pheromone on the paths that have a high heuristic value but then find the paths that violate constraints less. After several generations, the pheromone will build up over one path and all ants will converge upon it. The downside to this approach is that the ACO values exploitation too highly and results in a sub optimal convergence. It is also plausible to consider that the heuristic value used by ACO is not ideal and is responsible for preventing further exploration. For future consideration is implementing an ACO metaheuristic that dynamically decrease the heuristic influence over time/generations in favour of random exploration, or potentially consider different heuristics, ie. a second heuristic that rewards candidates with less penalty violations is introduced.

Experimentation with the ACO pheromone matrix was performed by resetting the pheromone matrix but leaving the population seeded with its best dimension set. This activity had no effect on the convergence path of ACO as ants consistently followed the same set of decisions to build up the pheromone matrix again and came to the same solution quality.

Dorigo's ACS implementation (Dorigo \& Gambardella, 1997) or Stutzle and Hoos MAX-Min ant system implementation (Stützle \& Hoos, 2000) have both been proven to overcome the shortfalls of AS and are hypothesised to provide improvements in performance quality to this problem. 


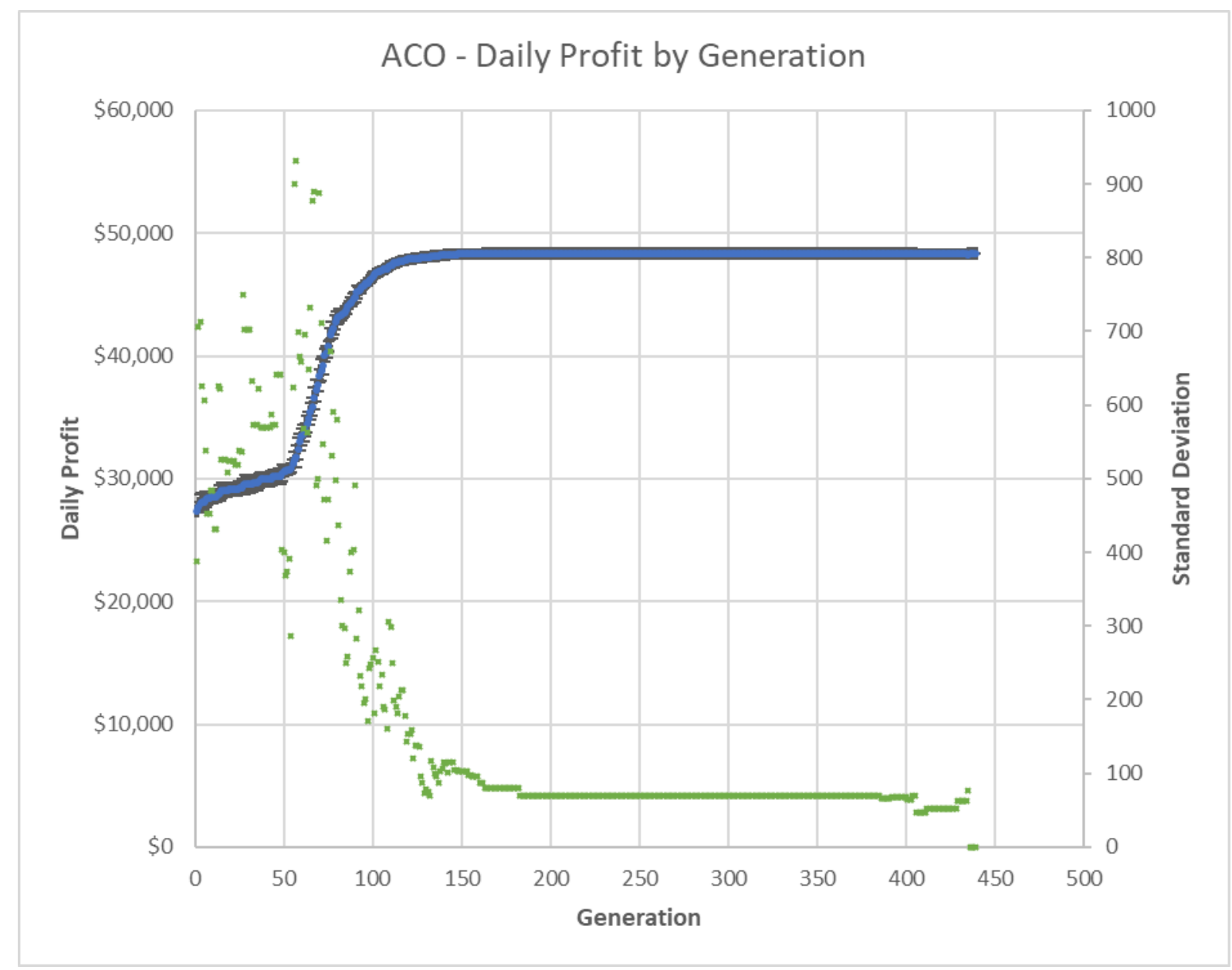

Figure 10 - Improvement in profit over generations for the ACO approach

The very fast convergence pattern is commonly identified in literature and is considered a typical AS convergence path (Dorigo \& Gambardella, 1997) and there is opportunity here to improve the performance of ACO by better controlling the convergence rate, such as using $\alpha$ annealing (Meyer, 2004a).

\section{Critical Analysis}

Figure 11 - Comparison of approaches; profit by generation convergence. compares the performance of each metaheuristic. What we see displayed here is that each metaheuristic has a distinct and consistent convergence pattern as well as a distinct and consistent first-generation performance. The two immediate observations, with the first being that ACO is extremely rapid in identifying performance improvements initially. In fact, given that the best seeded candidate scores in generation 0 will have been around $11 \mathrm{k}$, ACO was able to consistently achieve a score of at least double that after the first generation, this is a unique advantage that ACO has over the other techniques. The second immediate observation is that the GA was able to significantly outperform the other methods in terms of quality. 


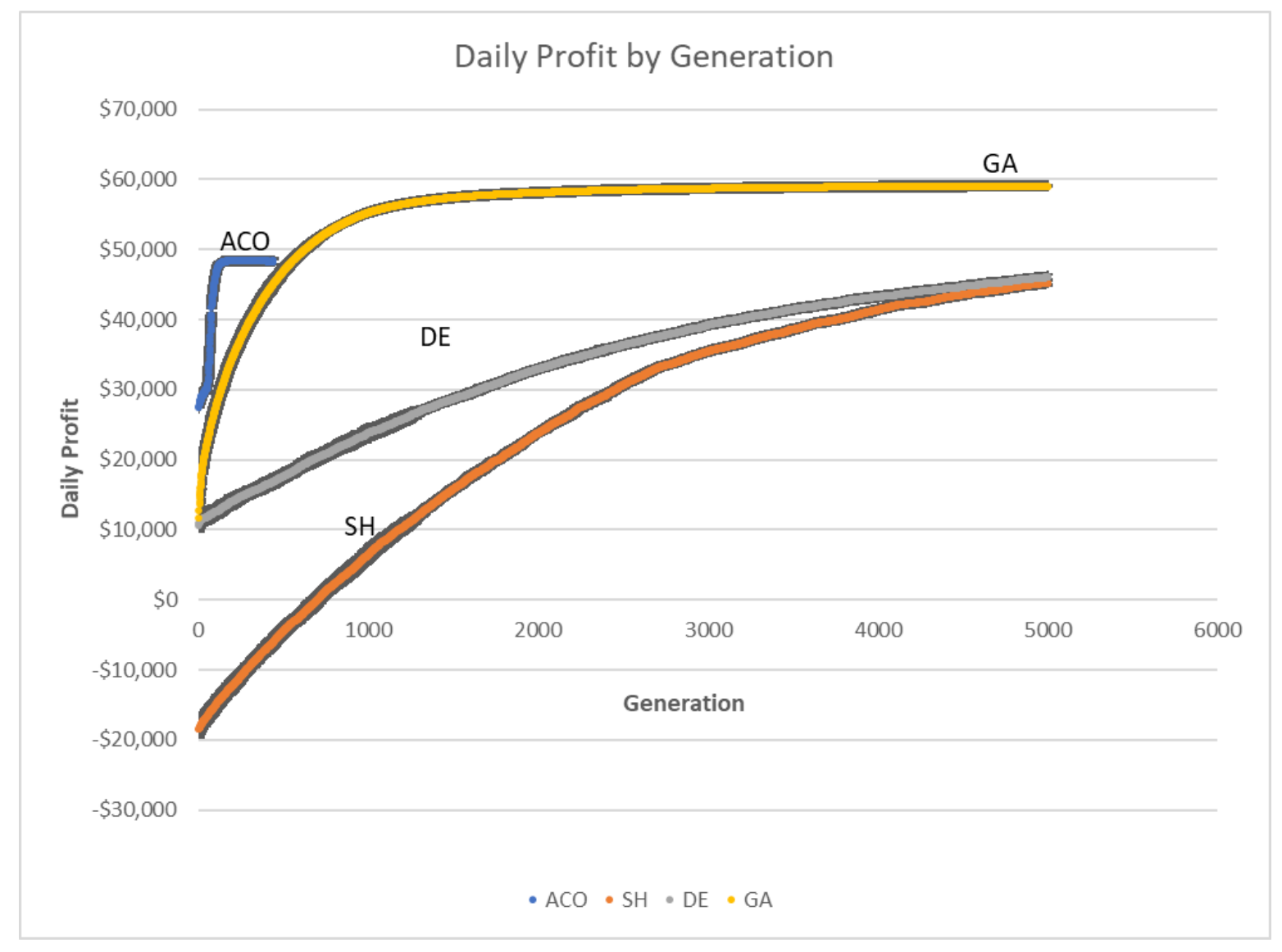

Figure 11 - Comparison of approaches; profit by generation convergence.

Further investigation is required to explore different implementation methods for each of the metaheuristics considered as it is clear from the literature that improvements in performance can be achieved by applying different mechanics (several which have been mentioned throughout this paper). However, from the specific implementations analysed a solution can be proposed that has been proven to outperform conventional methods. The following paragraph propose a hybrid metaheuristic that leverages aspects from each approach to achieve an optimal convergence.

A metaheuristic that loosely couples the GA and ACO implementations could be used to the greatest effect. Loose coupling means there is no integration between the two metaheuristics other than the population of candidate's genetic material is passed from one algorithm to the next. Simply put this would involve running ACO first to leverage the early performance gains and then passing the candidate population across to the GA which would then proceed to find an optimal solution. The point of coupling would occur when the ACO algorithm converges.

The next figure, Figure 12 - Metaheuristic performance by CPU time, compares the four techniques in terms of solution quality by CPU time. We see a very similar story for ACO, GA and SH, in terms of convergence paths and time to converge. This shows that the DE implementation is particularly weak in terms of convergence time with further justification being given to its exclusion from recommendation. 


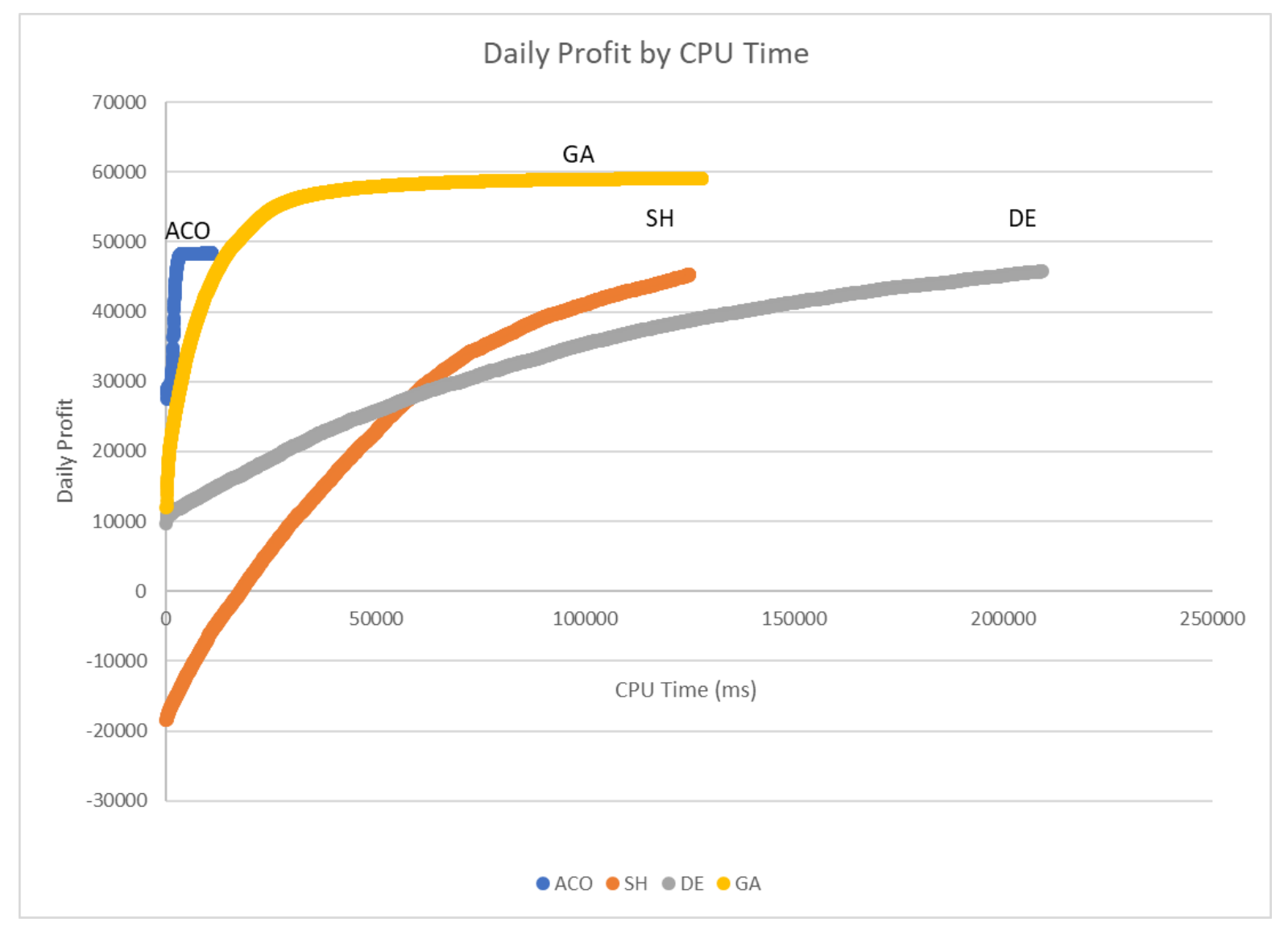

Figure 12 - Metaheuristic performance by CPU time

\section{Results of Survey and Literature Review}

As mentioned briefly in the introduction - the process of identifying suitable Al techniques was the first step performed in this research and is merits discussion regarding some key findings. It might be assumed that GA's were the most prolific technique since they have been around the longest. While this may be a factor, The GA literature reviewed was all within the last 15 years and was still abundant so implies that there are other factors. A qualitative assessment of the literature has led to an understanding that other key factors play a part in GA's selection for VMI type problems. These are the simplicity to understand and implement GA's, the native suitability of GA algorithms for these kinds of problems, and the general flexibility of the GA metaheuristic.

ACO literature was less common that GA literature but still readily available however the types of problems were not easily translatable to the problem reviewed in this paper. Often ACO was applied to the traveling salesman or Knapsack styled optimisation problems. As previously highlighted in the literature review, one of the more intriguing methods using ACO for a VMI optimisation problem was using Pareto ACO (Moncayo-Martínez \& Zhang, 2011), for solving multi objective optimisation. This couple with a proposal (Coello, 2000) of considering constraints as objective functions could warrant further investigation in this problem space.

Literature specifically applying DE's to VMI problems was particularly scare and this is most likely due to the unsuitability of a continuous optimising technique for discrete spaces.

Appendices $A$ and $B$ provide these tabulated findings. 


\section{CONCLUSIONS}

Of the Al techniques and the implementations of those techniques considered, a loosely coupled hybrid ACO-GA would achieve the fastest convergence and greatest performance quality as well as minimum compute time required. The recommended approach to take is to first implement ACO and to incorporate very tight convergence rule. When ACO converges swap to GA to achieve greater performance quality. Finally, determine appropriate GA convergence rules for the business requirements that trades off time to compute for additional gains. In other words, determine at what point marginal increases in performance quality are no longer significant to justify the time to compute.

Regarding general adaptability to similar problems, GA is the recommended implementation approach (of the approaches investigated) as it was significantly faster to build, adapt and tune than ACO and $D E$ along with outperforming in terms of solution quality. There is room for significant improvements in the ACO technique by applying more modern variants, which may (or may not) outperform the GA approach and would require further investigation to determine. Also, it is worth noting that the ACO AS implementation may be suitable for this problem where substantially bigger data set were involved given its ability to rapidly find a solution, this is an opportunity to further investigate this problem using larger data sets. The DE approach was ineffective due to the implementation selected, however based on the challenges in adapting a continuous search optimisation metaheuristic to a discrete problem and the results of this experimentation it is concluded that DE is not appropriate for this problem.

The data used for this problem did not considering seasonality, weekly fluctuations or any other variations in demand and therefor assuming constant demand. Therefore, it is possible to annualise the performance of each technique to a dollar amount for this data set. While the data set has been strongly obfuscated, it has been realistically adapted based on business rules previously defined and is suitable for drawing the following conclusions.

The baseline SH search yielded approximately $45 \mathrm{~K}$ daily, as an annualised figure $(50 \mathrm{~K} * 365)$ this comes to approximately 16.4 Million. By comparison the GA came to an approximately annual figure of 21.9 Million $(60 \mathrm{~K} * 365)$ - A difference of 4.4 Million. While this is not a comparison against human performance it provides indicative improvements over less powerful techniques and provides insight into the potential benefits of implementing these techniques.

This model is significantly constrained and obfuscated which prevents its comparison by human performance. Future studies would release the model constraints by including more model parameters and the loosening up of assumptions (such as lead time, and forecasts greater than next day) and running the model against a comparable data set. Furthermore, developing an improved consensus forecasting method to provide the forecast distribution as an input to the optimisation model. Drawing on techniques proposed in existing literature such as Machine Learning Techniques (Carbonneau, Laframboise, \& Vahidov, 2008), Neural Networks (Zhang, Eddy Patuwo, \& Y. Hu, 1998), (Cheng, Hai-Wei, \& Chen, 2006), (Efendigil, Önüt, \& Kahraman, 2009), Support Vector Machines (Yue, Yafeng, Junjun, \& Chongli, 2007) and Bayesian Forecasting (Korb \& Nicholson, 2010), (Vercher, 2010)

As the models themselves were only tested on a single data set, the conclusions that can be drawn are limited. The scalability of the heuristics to different data sets and larger data sets has not been validated by this study and future studies would involve the comparison of these techniques against a variety of data sets. Support for scalability would be a consideration to be investigated, such as parallel design and processing to handle larger data sets (Thiruvady, Ernst, \& Singh, 2016). 


\section{REFERENCES}

Akbari Kaasgari, M., Imani, D. M., \& Mahmoodjanloo, M. (2017). Optimizing a vendor managed inventory (VMI) supply chain for perishable products by considering discount: Two calibrated meta-heuristic algorithms. Computers \& Industrial Engineering, 103, 227-241. doi:10.1016/j.cie.2016.11.013

Arora, V., Chan, F. T. S., \& Tiwari, M. K. (2010). Corrigendum to "An integrated approach for logistic and vendor managed inventory in supply chain" [Expert Systems with Applications 37 (1) (2010) 39-44]. Expert Systems With Applications, $37(6)$,

4719. doi:https://doi.org/10.1016/j.eswa.2009.11.063

Borade, A. B., \& Sweeney, E. (2014). Decision support system for vendor managed inventory supply chain: a case study. International Journal of Production Research, 1-30. doi:10.1080/00207543.2014.993047

Carbonneau, R., Laframboise, K., \& Vahidov, R. (2008). Application of machine learning techniques for supply chain demand forecasting. European Journal of Operational Research, 184(3), 1140-1154. doi:https://doi.org/10.1016/j.ejor.2006.12.004

Cardenas-Barron, L., Trevino-Garza, G., \& Wee, H. M. (2012). A simple and better algorithm to solve the vendor managed inventory control system of multiproduct multi-constraint economic order quantity model. Expert Syst. Appl., 39(3), 3888-3895. doi:10.1016/j.eswa.2011.09.057

Chehouri, A., Younes, R., Perron, J., \& Ilinca, A. (2016). A Constraint-Handling Technique for Genetic Algorithms using a Violation Factor. Journal of Computer Science, 12(7), 350-362. doi:10.3844/jcssp.2016.350.362

Chen, S., Montgomery, J., \& Bolufé-Röhler, A. (2015). Measuring the curse of dimensionality and its effects on particle swarm optimization and differential evolution. The International Journal of Artificial Intelligence, Neural Networks, and Complex Problem-Solving Technologies, 42(3), 514526. doi:10.1007/s10489-014-0613-2

Cheng, Y. H., Hai-Wei, L., \& Chen, Y. S. (2006, 21-23 June 2006). Implementation of a Back-Propagation Neural Network for Demand Forecasting in a Supply Chain - A Practical Case Study. Paper presented at the 2006 IEEE International Conference on Service Operations and Logistics, and Informatics.

Chi, H.-M., Ersoy, O. K., Moskowitz, H., \& Ward, J. (2007). Modeling and optimizing a vendor managed replenishment system using machine learning and genetic algorithms. European Journal of Operational 
Research,

180(1),

174-193.

doi:http://dx.doi.org/10.1016/j.ejor.2006.03.040

Coello, C. A. C. (2000). Treating constraints as objectives for single-objective evolutionary optimization. Engineering Optimization+ A35, 32(3), 275-308.

Das, S., Mullick, S. S., \& Suganthan, P. N. (2016). Recent advances in differential evolution-an updated survey. Swarm and Evolutionary Computation, 27, 1-30.

Deb, K., Pratap, A., Agarwal, S., \& Meyarivan, T. (2002). A fast and elitist multiobjective genetic algorithm: NSGA-II. Evolutionary Computation, IEEE Transactions on, 6(2), 182-197. doi:10.1109/4235.996017

Diabat, A. (2014). Hybrid algorithm for a vendor managed inventory system in a two-echelon supply chain. European Journal of Operational Research, 238(1), 114-121. doi:http://doi.org/10.1016/j.ejor.2014.02.061

Disney, S. M., \& Towill, D. R. (2003). The effect of vendor managed inventory (VMI) dynamics on the Bullwhip Effect in supply chains. International Journal of Production Economics, 85(2), 199-215. doi:10.1016/S09255273(03)00110-5

Dorigo, M. (2004). Ant colony optimization. Cambridge, Mass.

Dorigo, M., \& Gambardella, L. M. (1997). Ant colony system: a cooperative learning approach to the traveling salesman problem. IEEE Transactions on evolutionary computation, 1(1), 53-66.

Dyer, J. H., \& Singh, H. (1998). The relational view: Cooperative strategy and sources of interorganizational competitive advantage. Academy of management review, 23(4), 660-679.

Efendigil, T., \& Önüt, S. (2011). An integration methodology based on fuzzy inference systems and neural approaches for multi-stage supply-chains. Computers \&amp; Industrial Engineering. doi:10.1016/j.cie.2011.11.004

Efendigil, T., Önüt, S., \& Kahraman, C. (2009). A decision support system for demand forecasting with artificial neural networks and neuro-fuzzy models: A comparative analysis. Expert Systems With Applications, 36(3, Part 2), 6697-6707. doi:https://doi.org/10.1016/j.eswa.2008.08.058

Gao, D., Xu, Z., Ruan, Y. Z., \& Lu, H. (2017). From a systematic literature review to integrated definition for sustainable supply chain innovation (SSCI). Journal of Cleaner Production, 142, 1518-1538. doi:10.1016/j.jclepro.2016.11.153

Goldberg, D. E. (1989). Genetic algorithms in search, optimization, and machine learning: Reading, Mass : Addison-Wesley.

Haven, E., Liu, X., \& Shen, L. (2012). De-noising option prices with the wavelet method. European Journal of Operational Research, 222(1), 104-112. doi:10.1016/j.ejor.2012.04.020 
Holland, J. (1984). Genetic algorithms and adaptation. In Adaptive Control of IIIDefined Systems (pp. 317-333): Springer.

Holland, J. (1992). Adaptation in natural and artificial systems : an introductory analysis with applications to biology, control, and artificial intelligence. Cambridge, Mass.: Cambridge, Mass. : MIT Press.

Kastsian, D., \& Mönnigmann, M. (2011). Optimization of a vendor managed inventory supply chain with guaranteed stability and robustness. International Journal of Production Economics, 131(2), 727-735. doi:10.1016/j.ijpe.2011.02.022

Korb, K. B., \& Nicholson, A. E. (2010). Bayesian artificial intelligence: CRC press.

Kristianto, Y., Helo, P., Jiao, J., \& Sandhu, M. (2012). Adaptive fuzzy vendor managed inventory control for mitigating the Bullwhip effect in supply chains. European Journal of Operational Research, 216(2), 346.

Kwak, C., Choi, J. S., Kim, C. O., \& Kwon, I.-H. (2009). Situation reactive approach to Vendor Managed Inventory problem. Expert Systems With Applications, 36(5), 9039-9045. doi:10.1016/j.eswa.2008.12.018

Kwon, O., Im, G. P., \& Lee, K. C. (2008). Corrigendum to "MACE-SCM: A multiagent and case-based reasoning collaboration mechanisms for supply chain management under supply and demand uncertainties" [Expert Systems with Applications 33 (3) (2007) 690-705]. Expert Systems With Applications, 34(3), 2229. doi:https://doi.org/10.1016/i.eswa.2007.10.002 Lampinen, J., \& Zelinka, I. (1999). Mixed integer-discrete-continuous optimization by differential evolution. Paper presented at the Proceedings of the 5th International Conference on Soft Computing.

Lau, H. C. W., Wan Kai, P., \& Christina, W. Y. W. (2002). Methodology for monitoring supply chain performance: a fuzzy logic approach. Logistics Information Management, 15(4), 271-280. doi:10.1108/09576050210436110

Liao, S.-H., Hsieh, C.-L., \& Lai, P.-J. (2011). An evolutionary approach for multiobjective optimization of the integrated location-inventory distribution network problem in vendor-managed inventory. Expert Systems With Applications, 38(6), 6768-6776. doi:10.1016/j.eswa.2010.12.072

Lin, K.-P., Chang, P.-T., Hung, K.-C., \& Pai, P.-F. (2010). A simulation of vendor managed inventory dynamics using fuzzy arithmetic operations with genetic algorithms.(Report). Expert Systems With Applications, 37(3), 2571.

Mateo, \& Aghezzaf, M. E. H. (2014). Integrating Vendor Managed Inventory and Cooperative Game Theory to Effectively Manage Supply Networks. In (pp. 263-288). 
McAdam, R., \& Keogh, W. (2004). Transitioning Towards Creativity and Innovation Measurement in SMEs. Creativity and Innovation Management, 13(2), 126-139. doi:10.1111/j.0963-1690.2004.00300.x

Meyer, B. (2004a). Convergence control in ACO. Paper presented at the Genetic and Evolutionary Computation Conference (GECCO), Seattle, WA, latebreaking paper available on $\mathrm{CD}$.

Meyer, B. (2004b). On the convergence behaviour of ant colony search. Paper presented at the Asia-Pacific Conference on Complex Systems.

Michalewicz, Z. (1995). Genetic algorithms, numerical optimization, and constraints. Paper presented at the Proceedings of the sixth international conference on genetic algorithms.

Moncayo-Martínez, L. A., \& Zhang, D. Z. (2011). Multi-objective ant colony optimisation: A meta-heuristic approach to supply chain design. International Journal of Production Economics, 131(1), 407-420. doi:10.1016/j.ijpe.2010.11.026

Mondal, S., \& Maiti, M. (2003). Multi-item fuzzy EOQ models using genetic algorithm. Computers \& Industrial Engineering, 44(1), 105-117. doi:10.1016/S0360-8352(02)00187-0

Ortiz, F., Simpson, J., Pignatiello, J., \& Heredia-Langner, A. (2004). A Genetic Algorithm Approach to Multiple-Response Optimization. Journal of Quality Technology, 36(4), 432-450.

Pan, Q.-K., Tasgetiren, M. F., \& Liang, Y.-C. (2008). A discrete differential evolution algorithm for the permutation flowshop scheduling problem. Computers \& Industrial Engineering, 55(4), 795-816.

Park, Y.-B., Yoo, J.-S., \& Park, H.-S. (2016). A genetic algorithm for the vendormanaged inventory routing problem with lost sales. Expert Systems With Applications, 53(Supplement $\quad$ C), 149-159. doi:https://doi.org/10.1016/j.eswa.2016.01.041

Pasandideh, S. H. R., Niaki, S. T. A., \& Nia, A. R. (2011). A genetic algorithm for vendor managed inventory control system of multi-product multiconstraint economic order quantity model. Expert Systems With Applications, 38(3), 2708-2716. doi:10.1016/j.eswa.2010.08.060

Pino, R., Fernández, I., de La Fuente, D., Parreño, J., \& Priore, P. (2010). Supply chain modelling using a multi-agent system. Journal of Advances in Management Research, 7(2), 149-162. doi:10.1108/09727981011084968

Price, K. V. a. (2005). Differential Evolution A Practical Approach to Global Optimization: Berlin, Heidelberg : Springer Berlin Heidelberg.

Roozbeh Nia, A., Hemmati Far, M., \& Akhavan Niaki, S. T. (2014). A fuzzy vendor managed inventory of multi-item economic order quantity model under 
shortage: An ant colony optimization algorithm. International Journal of Production Economics, 155, 259-271. doi:10.1016/j.ijpe.2013.07.017

Routroy, S., \& Kodali, R. (2005). Differential evolution algorithm for supply chain inventory planning. Journal of Manufacturing Technology Management, 16(1), 7-17. doi:10.1108/17410380510574059

Rylander, S. G. B. (2002). Optimal population size and the genetic algorithm. Population, 100(400), 900.

Sadeghi, J., Sadeghi, S., \& Niaki, S. T. A. (2014). Optimizing a hybrid vendormanaged inventory and transportation problem with fuzzy demand: An improved particle swarm optimization algorithm. Information Sciences, 272, 126-144. doi:http://dx.doi.org/10.1016/j.ins.2014.02.075

Sari, K. (2017). Modeling of a Fuzzy Expert System for Choosing an Appropriate Supply Chain Collaboration Strategy. Intelligent Automation \& Soft Computing, 1-8. doi:10.1080/10798587.2017.1352258

Shafieezadeh, M., \& Sadegheih, A. (2014). Developing an integrated inventory management model for multi-item multi-echelon supply chain. The International Journal of Advanced Manufacturing Technology, 72(5-8), 1099-1119. doi:10.1007/s00170-014-5684-z

Silva, J. M. G. S., Sousa, J. M. G. S., Sa Da Costa, J. M. G. S., \& Runkler, J. M. G. S. (2004). A multi-agent approach for supply chain management using ant colony optimization. In (Vol. 2, pp. 1938-1943).

Stützle, T., \& Hoos, H. H. (2000). MAX-MIN ant system. Future generation computer systems, 16(8), 889-914.

Sue-Ann, G., Ponnambalam, S. G., \& Jawahar, N. (2012). Evolutionary algorithms for optimal operating parameters of vendor managed inventory systems in a two-echelon supply chain. Advances in Engineering Software, 52, 47-54. doi:10.1016/j.advengsoft.2012.06.003

Sui, Z., Gosavi, A., \& Lin, L. (2010). A Reinforcement Learning Approach for Inventory Replenishment in Vendor-Managed Inventory Systems With Consignment Inventory. Engineering Management Journal, 22(4), 44-53. doi:10.1080/10429247.2010.11431878

Thiruvady, D., Ernst, A. T., \& Singh, G. (2016). Parallel ant colony optimization for resource constrained job scheduling. Annals of Operations Research, 242(2), 355-372.

Vercher, E. (2010). Bayesian forecasting with the HoltWinters model. Journal of the Operational Research Society, 61(1), 164-171. doi:10.1057/jors.2008.152

Vieira, D. A. G., Adriano, R. L. S., Vasconcelos, J. A., \& Krahenbuhl, L. (2004). Treating constraints as objectives in multiobjective optimization problems 
using niched Pareto genetic algorithm. Magnetics, IEEE Transactions on, 40(2), 1188-1191. doi:10.1109/TMAG.2004.825006

Voratas, K. (2012). Comparison of Three Evolutionary Algorithms: GA, PSO, and DE. Industrial Engineering and Management Systems, 11(3), 215 223.

Wisittipanich, W., \& Kachitvichyanukul, V. (2012). Two enhanced differential evolution algorithms for job shop scheduling problems. International Journal of Production Research, 50(10), 2757-2773. doi:10.1080/00207543.2011.588972

Yang, J., Xie, B., \& Sha, Q. (2010). Research and application of BP Neural Networks in Collaborative Supply Chain VMI\&\#039; s customer demanding. In (pp. 348-353).

Yeniay, Ö. (2005). Penalty function methods for constrained optimization with genetic algorithms. Mathematical and computational Applications, 10(1), 45-56.

Yue, L., Yafeng, Y., Junjun, G., \& Chongli, T. (2007, 24-27 Aug. 2007). Demand Forecasting by Using Support Vector Machine. Paper presented at the Third International Conference on Natural Computation (ICNC 2007).

Zhang, G., Eddy Patuwo, B., \& Y. Hu, M. (1998). Forecasting with artificial neural networks:: The state of the art. International Journal of Forecasting, 14(1), 35-62. doi:10.1016/S0169-2070(97)00044-7

Zhou, Z., \& Harris, K. D. M. (2008). Counteracting stagnation in genetic algorithm calculations by implementation of a micro genetic algorithm strategy. Physical Chemistry Chemical Physics, 10(48), $7262-7269$. doi:10.1039/b807326k 


\section{APPENDIX A TO COMPARING GA, DE AND ACO FOR VENDOR MANAGED INVENTORY OPTIMISATION}

\section{Survey of literature for Al technique selection}

\begin{tabular}{|c|c|c|c|}
\hline Approach & Area Applied & References & Count \\
\hline $\begin{array}{l}\text { Artificial Neural } \\
\text { Networks }\end{array}$ & Demand Forecasting & $\begin{array}{l}\text { (Cheng et al., 2006; Efendigil \& } \\
\text { Önüt, 2011; Yang, Xie, \& Sha, } \\
\text { 2010; Zhang et al., 1998) }\end{array}$ & 4 \\
\hline Expert Systems & Modelling & (Sari, 2017) & 1 \\
\hline Wavelets & $\begin{array}{l}\text { Estimating Unknown } \\
\text { Parameters and Data } \\
\text { Cleansing (Scale and } \\
\text { Noise) }\end{array}$ & (Haven, Liu, \& Shen, 2012) & 1 \\
\hline $\begin{array}{l}\text { Adaptive Neuro- } \\
\text { Fuzzy Inference } \\
\text { System (ANFIS) }\end{array}$ & Demand Forecasting & (Efendigil \& Önüt, 2011) & 1 \\
\hline $\begin{array}{l}\text { Machine Learning - } \\
\text { SVM }\end{array}$ & $\begin{array}{l}\text { Modelling, Demand } \\
\text { Forecasting }\end{array}$ & (Chi et al., 2007; Yue et al., 2007) & 2 \\
\hline Fuzzy Logic & $\begin{array}{l}\text { Demand Forecasting, } \\
\text { Vendor Performance } \\
\text { Classification, Modelling }\end{array}$ & $\begin{array}{l}\text { (Lau, Wan Kai, \& Christina, 2002; } \\
\text { Sadeghi, Sadeghi, \& Niaki, 2014; } \\
\text { Sari, 2017) }\end{array}$ & 3 \\
\hline Agent Based Systems & Collaboration & (Kwon, Im, \& Lee, 2008) & 1 \\
\hline Bayesian Network & $\begin{array}{l}\text { Modelling, Demand } \\
\text { Forecasting }\end{array}$ & (Vercher, 2010) & 1 \\
\hline Genetic Algorithms & Optimisation & $\begin{array}{l}\text { (Borade \& Sweeney, 2014; Chi et } \\
\text { al., 2007; Liao et al., 2011; Park et } \\
\text { al., 2016; Roozbeh Nia et al., } \\
\text { 2014; Sue-Ann et al., 2012) }\end{array}$ & 5 \\
\hline $\begin{array}{l}\text { Automated } \\
\text { intelligent } \\
\text { management system } \\
\text { (AIMS) }\end{array}$ & & (Chi et al., 2007) & 1 \\
\hline $\begin{array}{l}\text { Ant Colony } \\
\text { Optimisation }\end{array}$ & Optimisation & $\begin{array}{l}\text { (Arora et al., 2010; Roozbeh Nia } \\
\text { et al., 2014) }\end{array}$ & 2 \\
\hline Differential Evolution & Optimisation & (Roozbeh Nia et al., 2014) & 1 \\
\hline $\begin{array}{l}\text { Reinforcement } \\
\text { Learning }\end{array}$ & Replenishment Policy & (Sui, Gosavi, \& Lin, 2010) & 1 \\
\hline $\begin{array}{l}\text { Particle Swarm } \\
\text { Optimisation }\end{array}$ & Optimisation & (Sue-Ann et al., 2012) & 1 \\
\hline Game Theory & Optimisation & (Mateo \& Aghezzaf, 2014) & 1 \\
\hline $\begin{array}{l}\text { MAS Multi Agent } \\
\text { Systems }\end{array}$ & Modelling & $\begin{array}{l}\text { (Pino, Fernández, de La Fuente, } \\
\text { Parreño, \& Priore, 2010) }\end{array}$ & 1 \\
\hline
\end{tabular}




\section{APPENDIX B TO COMPARING GA, DE AND ACO FOR VENDOR MANAGED INVENTORY OPTIMISATION}

Detailed literature review survey

\begin{tabular}{|c|c|c|c|c|c|c|c|c|c|c|c|c|c|c|c|c|c|c|c|}
\hline \multirow{3}{*}{$\begin{array}{l}\text { Atribibute } \\
\text { Demand }\end{array}$} & Values & $\begin{array}{l}\mid c \text { case study } \\
\text { se }\end{array}$ & 11 & {$[2]$} & [3] & $\frac{447}{46}$ & [5] & [6] & [1] & {$[8]$} & [9] & {$[10]$} & [11] & {$[112]$} & [13] & [14] & [15] & [16] & [17] \\
\hline & Stochassitic & \begin{tabular}{|c|}
$x$ \\
\end{tabular} & $x$ & $x$ & & 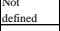 & & $\mathrm{x}$ & $\sqrt{6}$ & NA & $x$ & & & $\times$ & 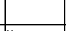 & $\mathrm{x}$ & $x$ & & \\
\hline & Deterministic & & & & $\begin{array}{c}x \\
x\end{array}$ & & & & $x$ & & & & $x^{x}$ & 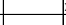 & $x$ & & 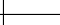 & & \\
\hline \multirow{2}{*}{ Num Suppliers } & Single & & $x$ & 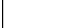 & 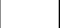 & 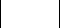 & $\begin{array}{l}\text { Not } \\
\text { defined } \\
\text { ding }\end{array}$ & $\mathrm{x}$ & $\begin{array}{l}\text { Not } \\
\text { defined } \\
\text { D. }\end{array}$ & NA & NA & Noi Definat & $\begin{array}{l}\text { Not } \\
\text { Dofinind }\end{array}$ & 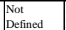 & 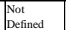 & 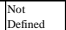 & NA & & $x$ \\
\hline & multi & & & $\begin{array}{ll}x \\
x\end{array}$ & $\begin{array}{l}x \\
x\end{array}$ & & & 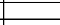 & & - & & & & & & & & & \\
\hline \multirow{2}{*}{ Num Distributors } & single & $x$ & & x & x & 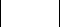 & x & 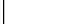 & $x$ & W & $x$ & Not Defined & $\mathrm{x}$ & $\mathrm{x}$ & Nor & $x$ & $x$ & & $\mathrm{x}$ \\
\hline & Multi & & & & & $x$ & & $x^{x}$ & & (n) & & & E & & & $\bar{E}$ & & & \\
\hline \multirow[t]{2}{*}{ Num Customers } & single & & 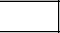 & x & 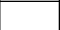 & 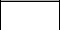 & $\mathrm{x}$ & 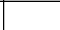 & 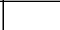 & 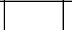 & 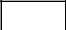 & $x_{x}$ & $\mathrm{x}$ & $\mathrm{x}$ & 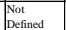 & 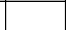 & $x$ & & $x$ \\
\hline & Multi & & $x$ & & $x$ & $x$ & $\square_{1}$ & $x$ & $x$ & NAA & $x$ & 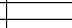 & $\mathrm{C}$ & $\square$ & & $x$ & & $x^{x}$ & 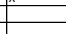 \\
\hline \multirow{2}{*}{ Backorders } & $\mathrm{y}$ & & 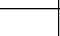 & $\mathrm{x}$ & 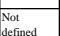 & $\mathrm{x}$ & 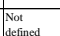 & $\begin{array}{l}\text { Not } \\
\text { Nofifed } \\
\text { difs }\end{array}$ & 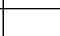 & NA & & $x$ & $x$ & $\begin{array}{l}\text { Not } \\
\text { Nefined }\end{array}$ & $\begin{array}{l}\text { Not } \\
\text { Notifned }\end{array}$ & 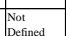 & $x$ & $x$ & \\
\hline & $x$ & & $x$ & $E$ & & $E$ & 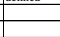 & 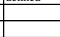 & $x^{x}$ & 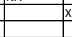 & $x$ & & E & 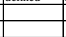 & 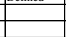 & 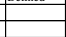 & - & & 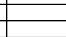 \\
\hline Delivery Time to Retailer & 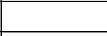 & Instanananeous & $\mathrm{NA}$ & $\begin{array}{l}\text { thatsiantaneo } \\
\text { us }\end{array}$ & $\mathrm{Y}$ & $\begin{array}{l}\text { Not } \\
\text { Defined } \\
\text { Dind }\end{array}$ & $\mathrm{y}^{\mathrm{s}}$ & $\begin{array}{l}\text { Not } \\
\text { dotined } \\
\text { ditand }\end{array}$ & 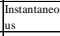 & NA & 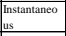 & Not Defined & 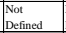 & $\begin{array}{l}\text { 仿ot } \\
\text { Defined } \\
\end{array}$ & $\begin{array}{l}\text { Not } \\
\text { Defined } \\
\text { Def }\end{array}$ & |lot & $r$ & $\begin{array}{l}\text { listatanter } \\
\text { us }\end{array}$ & r constant \\
\hline \multirow{2}{*}{ Distributors have Finite Resources } & & $\mathrm{N}$ & s & N & N & Y & $\mathrm{N}$ & $\mathrm{N}$ & $\mathrm{Y}$ & 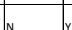 & y & 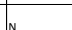 & 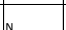 & & $\begin{array}{l}\text { Not } \\
\text { Nofifoct }\end{array}$ & $\mathrm{y}$ & Not & 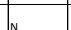 & \\
\hline & 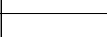 & N & Not & N & Not & Not & v & Not & $\gamma$ & 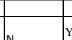 & & Noin Defined & Not & & Noot & Not & Not & Not & \\
\hline change in retailer price & & & & & & Min & & & & & & & & & & & & & \\
\hline \multirow[t]{4}{*}{ Num obiective functions } & one & Max. Profit & Min. cost & Min. cost & Min. cost & $\begin{array}{l}\text { transport } \\
\text { taion } \\
\text { cots }\end{array}$ & 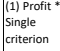 & Min cost & \begin{tabular}{|l|l} 
Max \\
Profit
\end{tabular} & Mresent & Win fost & Min cost & Min $\operatorname{cost}$ & Min cost & Min cost & 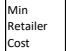 & Min cost & Min cost & Min cost \\
\hline & Iwo & & $\begin{array}{l}\text { Min. Loss } \\
\text { of Sales }\end{array}$ & & $\begin{array}{l}\text { Min. Lead } \\
\text { Times }\end{array}$ & 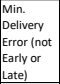 & $\begin{array}{l}\text { (2) Sales * } \\
\text { Multi } \\
\text { criterion }\end{array}$ & $\begin{array}{l}\text { Max } \\
\text { oemand } \\
\text { met }\end{array}$ & & $\begin{array}{l}\text { Total } \\
\text { Weighted } \\
\text { tardiness }\end{array}$ & & & & & & \begin{tabular}{|l} 
Min \\
Distribu \\
cost
\end{tabular} & & & \\
\hline & \multirow{2}{*}{ Threet } & & & & & $\begin{array}{l}\text { Min- } \\
\text { Overdue } \\
\text { ons }\end{array}$ & (2) $\operatorname{cost}^{*}$ & $\begin{array}{l}\text { Max.\%.\% } \\
\text { Demand }\end{array}$ & & & & & & & & \begin{tabular}{|c|c|} 
Max \\
Raterers
\end{tabular} & & & \\
\hline & & & & & & $\begin{array}{l}\text { Productio } \\
\text { nolos }\end{array}$ & \begin{tabular}{|l|l} 
Mutti \\
cutiteron
\end{tabular} & $\begin{array}{l}\text { met by a } \\
\text { cosesc }\end{array}$ & & & & & & & & Max Profit & & & \\
\hline \multirow{11}{*}{ eccision Varaible } & & & & & & & sertine & 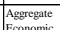 & & the & & & & & & & & & \\
\hline & & Qui & & Oreder & 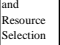 & $\begin{array}{l}\text { Not } \\
\text { Defined }\end{array}$ & 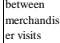 & 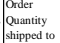 & $\begin{array}{l}\text { Ponter } \\
\text { Puannitice }\end{array}$ & $\begin{array}{l}\text { ticterese of } \\
\text { iof on on }\end{array}$ & 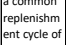 & forder & Order & Order & Order & lorder & Order & Oorder & order \\
\hline & & & & $\begin{array}{l}\text { Noumber o } \\
\text { palles }\end{array}$ & & & 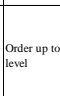 & & & $\begin{array}{ll}\text { the stat } \\
\text { tite of } \\
\text { iob on }\end{array}$ & 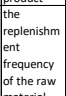 & & 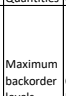 & order & & & Reorder & $\begin{array}{l}\text { Max } \\
\text { liventorn }\end{array}$ & Service \\
\hline & & & & $\begin{array}{l}\text { Maximum } \\
\text { backorder }\end{array}$ & & & $\begin{array}{l}\text { Time } \\
\text { betwen }\end{array}$ & & & & & & & $\begin{array}{l}\text { Shementery } \\
\text { Delivery }\end{array}$ & & & & Backorder & \\
\hline & & & & & & & $\begin{array}{l}\text { Spliphentert } \\
\text { lead ine }\end{array}$ & & & & & & & & & & 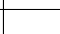 & & \\
\hline & & & & & & & 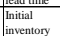 & & & & & & & & & & & & \\
\hline & & & & & & & 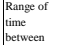 & & & & & & & & & & & & \\
\hline & & & & & & & 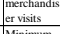 & & & & & & & & & & & & \\
\hline & & & & & & & 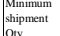 & & & & & & & & & & & & \\
\hline & & & & & & & $\begin{array}{l}\text { Day } \\
\text { thipments } \\
\text { the }\end{array}$ & & & & & & & & & & & & \\
\hline & & & & & & & & & & & & & & & & & & & \\
\hline \multirow{9}{*}{ constraints } & & & & & & & & Pestic & & & & & & & & & & & \\
\hline & $\begin{array}{rll}r & & \end{array}$ & & venicle & warenou & $\begin{array}{l}\text { Elfored } \\
\text { sequence }\end{array}$ & Not & 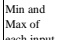 & 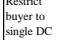 & \begin{tabular}{|l} 
Retailier \\
Rer
\end{tabular} & & critical & Retalier & Retalier & Retalier & Warehous & & & & \\
\hline & & & & & Activities & & 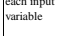 & $\begin{array}{l}\text { 霍 } \\
\text { posibible) }\end{array}$ & & 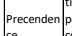 & 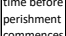 & & & & & Not & $\begin{array}{l}\text { Service } \\
\text { evel }\end{array}$ & Warebous & average \\
\hline & & & 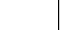 & & Restricting | & & & Enforce & & & & & & & 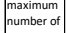 & & & & \\
\hline & N & & $\begin{array}{l}\text { Minimur } \\
\text { inventor }\end{array}$ & $\begin{array}{l}\text { Souding } \\
\text { Order }\end{array}$ & $\begin{array}{l}\text { Resources } \\
\text { to }\end{array}$ & & & $\begin{array}{l}\text { buver } \\
\text { assigmen } \\
\text { als }\end{array}$ & $\begin{array}{l}\text { vendor } \\
\text { Capactity }\end{array}$ & & & $\begin{array}{l}\text { Linition } \\
\text { cotal }\end{array}$ & 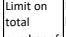 & 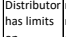 & $\begin{array}{l}\text { repenenish } \\
\text { ment }\end{array}$ & & & & \\
\hline & & & & & & & & $\begin{array}{l}\text { itiopen } \\
\text { ocs }\end{array}$ & & Confiticts & & 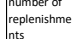 & $\begin{array}{l}\text { nemerer of } \\
\text { ments }\end{array}$ & 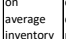 & 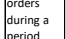 & & Packet & & \\
\hline & & & Retailer & 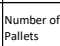 & & & & $\begin{array}{l}\text { Enforce } \\
\text { oc } \\
\text { copos }\end{array}$ & & & & & & $\begin{array}{l}\text { Liminit on } \\
\text { total }\end{array}$ & & & & & \\
\hline & & & & $\begin{array}{l}\text { and pallet } \\
\text { Capacity }\end{array}$ & & & & $\begin{array}{l}\text { capacty } \\
\text { restriction }\end{array}$ & & & & $\begin{array}{l}\text { Distributor } \\
\text { Grovity }\end{array}$ & Distributor & 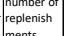 & & & Retailer & & \\
\hline & & & & & & & & 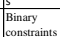 & & & & & & & & & & & \\
\hline & & & & & & & & & & & & & & & & & & & \\
\hline optimization Decision Variable(s) & Discretet (Binary) & & & & & & & x & 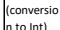 & & & & & & & & & & \\
\hline & $\begin{array}{l}\text { oiscrete (Integer) } \\
\text { continusus }\end{array}$ & & $x$ & $x^{x}$ & $x^{x}$ & $\mathrm{x}$ & 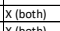 & . & & & & $x^{x}$ & $x^{x}$ & $x$ & $x$ & $x^{x}$ & $x$ & & $x$ \\
\hline & & & & & & & & & & & & & & & & & & & \\
\hline & & & & & Mutitive & Distribute & $\begin{array}{l}\text { linnout } \\
\text { multiti }\end{array}$ & $\mid \begin{array}{l}\text { Mutti- } \\
\text { Obiective }\end{array}$ & $\left|\begin{array}{l}\text { operating } \\
\text { Pramanter }\end{array}\right|$ & & & $\mid \begin{array}{l}\text { multi- } \\
\text { provitact }\end{array}$ & 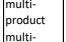 & & 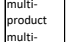 & Mutti & $\begin{array}{l}\text { single } \\
\text { buver }\end{array}$ & & \\
\hline blem Description & & & & & & & 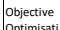 & Location-1 & Optimisati & & Persinible & multi- & $\begin{array}{l}\text { constraint } \\
\text { cotriluth }\end{array}$ & & $\begin{array}{l}\text { constraint } \\
\text { Oontivitut }\end{array}$ & $\begin{array}{l}\text { objective } \\
\text { becision }\end{array}$ & $\begin{array}{l}\text { suyere } \\
\text { single }\end{array}$ & & 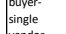 \\
\hline & & & & & Problem & $\begin{array}{l}\text { Problem } \\
\text { Proble }\end{array}$ & 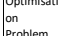 & 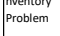 & $\begin{array}{l}\text { on } \\
\text { Problem } \\
\text { nate }\end{array}$ & job shop & 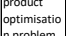 & 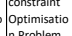 & 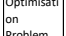 & & 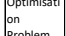 & Support & 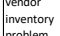 & & $\begin{array}{l}\text { veneor } \\
\text { inventry } \\
\text { nention }\end{array}$ \\
\hline & & & & & & & & & & & & & & & & & & & \\
\hline & & & & $A C O, 6 \mathrm{~A}$, & & 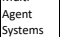 & & $\begin{array}{l}\text { Habrid } \\
\text { NSGA-II }\end{array}$ & & & & & & & & & & & \\
\hline dologies & & & DACO & $\begin{array}{l}\text { DE and } \\
\text { FNIP }\end{array}$ & aco & $\begin{array}{l}\text { Elmbedidec } \\
\text { with }\end{array}$ & GA & $\begin{array}{l}\text { hinuristic } \\
\text { assignmen }\end{array}$ & GA-Als & DE & & & & & & & & & \\
\hline & & & & & & aco & & & & & & GA & & & & & $G A$ & OE & DE \\
\hline 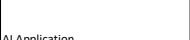 & & & Trensport & 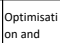 & $\begin{array}{l}\text { Suppliy } \\
\text { chain }\end{array}$ & $\begin{array}{l}\text { Suppoly } \\
\text { chan }\end{array}$ & $\begin{array}{l}\text { Supply } \\
\text { chan }\end{array}$ & $\begin{array}{l}\text { supply } \\
\text { chain }\end{array}$ & optit & 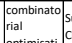 & $\begin{array}{l}\text { Supply } \\
\text { Chain }\end{array}$ & $\begin{array}{c}\text { Supply } \\
\text { chain }\end{array}$ & $\begin{array}{l}\text { Scoplin } \\
\text { chin }\end{array}$ & & $\begin{array}{l}\text { Supply } \\
\text { chanin }\end{array}$ & Supply & Supply & Supply & Supply \\
\hline & & & (DTSP) & $\begin{array}{l}\text { EFrocecastin } \\
g \text { Demand }\end{array}$ & $\begin{array}{l}\text { ofotimise } \\
\text { on }\end{array}$ & $\begin{array}{l}\text { ofitimi } \\
\text { on }\end{array}$ & $\begin{array}{l}\text { Ooptimis } \\
\text { on }\end{array}$ & $\begin{array}{l}\text { olditim } \\
\text { on }\end{array}$ & on & on & & $\begin{array}{l}\text { olotimi } \\
\text { not }\end{array}$ & $\begin{array}{l}\text { Ooptimis } \\
\text { on }\end{array}$ & & $\begin{array}{l}\text { Ootpimsi } \\
\text { on }\end{array}$ & potimisat & & & ottimisati \\
\hline oner & & & & & & & & & - & Productio & & & & & & & & & \\
\hline wentor Model & & & & & & & & & Eoa & , & & & & EPQ & Eoa & & & Eoa & \\
\hline
\end{tabular}




\section{APPENDIX C TO COMPARING GA, DE AND ACO FOR VENDOR MANAGED INVENTORY OPTIMISATION}

\section{Table of GA results}

\begin{tabular}{|c|c|c|c|c|c|c|c|c|c|c|c|c|c|c|}
\hline $\begin{array}{l}\text { Generation } \\
\text { Found }\end{array}$ & $\begin{array}{l}\text { Maximum } \\
\text { Generations }\end{array}$ & $\begin{array}{l}\text { Population } \\
\text { Size }\end{array}$ & $\begin{array}{l}\text { Candidate } \\
\text { Number }\end{array}$ & Score & $\begin{array}{l}\text { Raw } \\
\text { Margin }\end{array}$ & Total Cost & $\begin{array}{l}\mathrm{SOH} \\
\text { Cost }\end{array}$ & Obs Cost & $\begin{array}{l}\text { Holding } \\
\text { Cost }\end{array}$ & Availability & $\begin{array}{l}\text { Avail } \\
\text { Penalty }\end{array}$ & $\begin{array}{l}\text { Profit } \\
\text { Cost Ratio }\end{array}$ & $\begin{array}{l}\text { Proft Cost } \\
\text { Penalty }\end{array}$ & $\begin{array}{l}\text { Budget } \\
\text { Penalty }\end{array}$ \\
\hline 5131 & 7000 & 50 & 256544 & 59090.60 & 66873.47 & 1999982 & 0 & 5278.28 & 1450.09 & 0.95 & 58.14 & 0.03 & 996.36 & 0 \\
\hline 6215 & 7000 & 50 & 310750 & 59126.27 & 66838.53 & 1999851 & 0 & 5147.00 & 1446.90 & 0.95 & 124.58 & 0.03 & 993.77 & 0 \\
\hline 6561 & 7000 & 50 & 328039 & 59174.06 & 66897.62 & 1999982 & 0 & 5203.92 & 1450.97 & 0.95 & 74.75 & 0.03 & 993.92 & 0 \\
\hline 4677 & 7000 & 50 & 233846 & 59032.33 & 66745.14 & 1999954 & 0 & 5181.83 & 1442.68 & 0.95 & 91.36 & 0.03 & 996.95 & 0 \\
\hline 5153 & 7000 & 50 & 257636 & 59057.48 & 66744.69 & 1999993 & 0 & 5100.12 & 1450.74 & 0.95 & 141.20 & 0.03 & 995.15 & 0 \\
\hline 5298 & 7000 & 50 & 264851 & 59102.07 & 66864.68 & 1999990 & 0 & 5248.11 & 1460.28 & 0.95 & 58.14 & 0.03 & 996.09 & 0 \\
\hline 5641 & 7000 & 50 & 282040 & 59122.01 & 66898.55 & 1999987 & 0 & 5281.71 & 1441.10 & 0.95 & 58.14 & 0.03 & 995.60 & 0 \\
\hline 6279 & 7000 & 50 & 313923 & 59143.31 & 66859.82 & 1999935 & 0 & 5176.62 & 1454.30 & 0.95 & 91.36 & 0.03 & 994.23 & 0 \\
\hline 5820 & 7000 & 50 & 290980 & 59140.57 & 66851.11 & 1999760 & 0 & 5154.06 & 1454.75 & 0.95 & 107.97 & 0.03 & 993.76 & 0 \\
\hline 5407 & 7000 & 50 & 270335 & 59086.28 & 66792.46 & 1999483 & 0 & 5178.67 & 1440.86 & 0.95 & 91.36 & 0.03 & 995.29 & 0 \\
\hline
\end{tabular}




\section{APPENDIX D TO COMPARING GA, DE AND ACO FOR VENDOR MANAGED INVENTORY OPTIMISATION}

\section{Table of ACO results}

\begin{tabular}{|c|c|c|c|c|c|c|c|c|c|c|c|c|c|c|}
\hline $\begin{array}{l}\text { Generation } \\
\text { Found }\end{array}$ & $\begin{array}{l}\text { Maximum } \\
\text { Generations }\end{array}$ & $\begin{array}{l}\text { Population } \\
\text { Size }\end{array}$ & $\begin{array}{l}\text { Candidate } \\
\text { Number }\end{array}$ & Score & $\begin{array}{l}\text { Raw } \\
\text { Margin }\end{array}$ & Total Cost & $\begin{array}{l}\mathrm{SOH} \\
\mathrm{COSt}\end{array}$ & Obs Cost & $\begin{array}{l}\text { Holding } \\
\text { Cost }\end{array}$ & Availability & $\begin{array}{l}\text { Avail } \\
\text { Penalty }\end{array}$ & $\begin{array}{l}\text { Profit } \\
\text { Cost Ratio }\end{array}$ & $\begin{array}{l}\text { Proft Cost } \\
\text { Penalty }\end{array}$ & $\begin{array}{l}\text { Budget } \\
\text { Penalty }\end{array}$ \\
\hline 189 & 5000 & 50 & 102 & 48342.2 & 69540.97 & 2440974 & 0 & 6525.8 & 2161 & 0.949834 & 8.3056 & 0.019804 & 1479.3 & 11024.3 \\
\hline 162 & 5000 & 50 & 113 & 48322.8 & 69391.2 & 2432502 & 0 & 6541.87 & 2148 & 0.948173 & 91.362 & 0.019865 & 1474.54 & 10812.6 \\
\hline 150 & 5000 & 50 & 104 & 48337.4 & 69334.62 & 2427579 & 0 & 6619.69 & 2140.8 & 0.948505 & 74.751 & 0.019912 & 1472.54 & 10689.5 \\
\hline 169 & 5000 & 50 & 102 & 48321 & 69460.43 & 2436015 & 0 & 6502.09 & 2153.3 & 0.947841 & 107.97 & 0.019836 & 1475.69 & 10900.4 \\
\hline 163 & 5000 & 50 & 105 & 48387 & 69478.53 & 2438289 & 0 & 6462.27 & 2153.9 & 0.949169 & 41.528 & 0.019845 & 1476.64 & 10957.2 \\
\hline 163 & 5000 & 50 & 100 & 48333.5 & 69341.36 & 2432073 & 0 & 6447.35 & 2160.6 & 0.947508 & 124.58 & 0.019873 & 1473.48 & 10801.8 \\
\hline 163 & 5000 & 50 & 114 & 48246.2 & 69452.31 & 2441767 & 0 & 6496.86 & 2159 & 0.949502 & 24.917 & 0.019759 & 1481.22 & 11044.2 \\
\hline 143 & 5000 & 50 & 108 & 48431.1 & 69204.91 & 2417957 & 0 & 6522.2 & 2131.1 & 0.945847 & 207.64 & 0.02003 & 1463.95 & 10448.9 \\
\hline 140 & 5000 & 50 & 115 & 48450.7 & 68552.23 & 2389550 & 0 & 6344.12 & 2115.4 & 0.940864 & 456.81 & 0.020276 & 1446.37 & 9738.75 \\
\hline 183 & 5000 & 50 & 100 & 48229.8 & 69373.66 & 2435391 & 0 & 6554 & 2152.4 & 0.948505 & 74.751 & 0.019804 & 1477.94 & 10884.8 \\
\hline
\end{tabular}




\section{APPENDIX E TO COMPARING GA, DE AND ACO FOR VENDOR MANAGED INVENTORY OPTIMISATION}

\section{Table of DE results}

\begin{tabular}{|c|c|c|c|c|c|c|c|c|c|c|c|c|c|c|}
\hline $\begin{array}{l}\text { Generation } \\
\text { Found }\end{array}$ & $\begin{array}{l}\text { Maximum } \\
\text { Generations }\end{array}$ & $\begin{array}{l}\text { Population } \\
\text { Size }\end{array}$ & $\begin{array}{l}\text { Candidate } \\
\text { Number }\end{array}$ & Score & $\begin{array}{l}\text { Raw } \\
\text { Margin }\end{array}$ & Total Cost & $\begin{array}{l}\mathrm{SOH} \\
\text { Cost } \\
\end{array}$ & Obs Cost & $\begin{array}{l}\text { Holding } \\
\text { Cost }\end{array}$ & Availability & $\begin{array}{l}\text { Avail } \\
\text { Penalty }\end{array}$ & $\begin{array}{l}\text { Profit } \\
\text { Cost Ratio }\end{array}$ & $\begin{array}{l}\text { Proft Cost } \\
\text { Penalty }\end{array}$ & $\begin{array}{l}\text { Budget } \\
\text { Penalty }\end{array}$ \\
\hline 4992 & 5000 & 50 & 249636 & 45845 & 64828.03 & 2000100 & 0 & 14741.9 & 1532 & 0.921595 & 1420.3 & \begin{tabular}{|l|l|}
0.022921 \\
\end{tabular} & 1286.27 & 2.5 \\
\hline 4997 & 5000 & 50 & 249867 & 45366.5 & 64932.45 & 2000315 & 0 & 15495.9 & 1505.9 & 0.924917 & 1254.2 & 0.02268 & 1302.12 & 7.875 \\
\hline 4997 & 5000 & 50 & 249861 & 46265.3 & 64909.18 & 2002515 & 0 & 14404.4 & 1543.7 & 0.922924 & 1353.8 & 0.023104 & 1279.08 & 62.875 \\
\hline 4997 & 5000 & 50 & 249859 & 45635.9 & 64824.85 & 1999871 & 0 & 14911.6 & 1549.6 & 0.921262 & 1436.9 & 0.022819 & 1290.83 & 0 \\
\hline 4999 & 5000 & 50 & 249984 & 45506.5 & 64721.88 & 2000126 & 0 & 14742.8 & 1511.5 & 0.916611 & 1669.4 & 0.022752 & 1288.47 & 3.15 \\
\hline 4994 & 5000 & 50 & 249728 & 45959.8 & 65304.96 & 2002960 & 0 & 15616.5 & 1532.8 & 0.933555 & 822.26 & 0.022946 & 1299.73 & 74 \\
\hline 4991 & 5000 & 50 & 249567 & 45489.5 & 64634.02 & 1999964 & 0 & 14878.6 & 1534.6 & 0.921262 & 1436.9 & 0.022745 & 1294.46 & 0 \\
\hline 4989 & 5000 & 50 & 249453 & 45310.4 & 64189.48 & 1995455 & 0 & 14395.1 & 1540.2 & 0.916944 & 1652.8 & 0.022707 & 1290.9 & 0 \\
\hline 4983 & 5000 & 50 & 249173 & 45445.9 & 65004.98 & 1999889 & 0 & 15529.2 & 1524.4 & 0.925914 & 1204.3 & 0.022724 & 1301.15 & 0 \\
\hline 4986 & 5000 & 50 & 249332 & 45553.1 & 65133.85 & 2000081 & 0 & 15507.8 & 1535.6 & 0.925249 & 1237.5 & 0.022776 & 1297.84 & 2.025 \\
\hline
\end{tabular}

